US Army Corps of Engineers $s_{\circledast}$

Engineer Research and

Development Center

\title{
Predicting Service Life Utilizing Freeze-Thaw Modeling of Aging Navigation Structures
}

Jameson D. Shannon, Robert D. Moser, July 2019 and Stephanie G. Wood
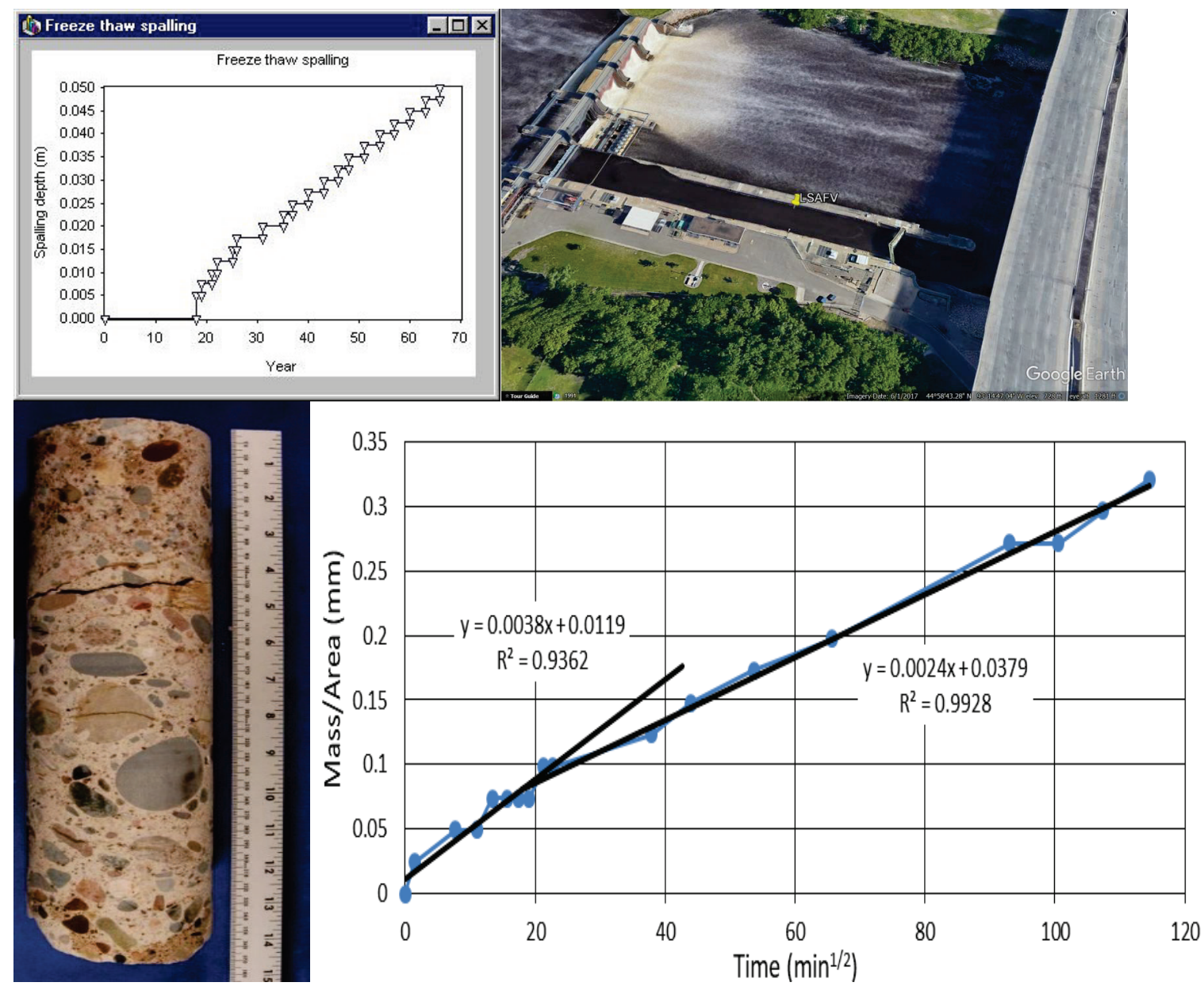
The U.S. Army Engineer Research and Development Center (ERDC) solves the nation's toughest engineering and environmental challenges. ERDC develops innovative solutions in civil and military engineering, geospatial sciences, water resources, and environmental sciences for the Army, the Department of Defense, civilian agencies, and our nation's public good. Find out more at www.erdc.usace.army.mil.

To search for other technical reports published by ERDC, visit the ERDC online library at http://acwc.sdp.sirsi.net/client/default. 


\section{Predicting Service Life Utilizing Freeze-Thaw Modeling of Aging Navigation Structures}

Jameson D. Shannon, Robert D. Moser, and Stephanie G. Wood

Geotechnical and Structures Laboratory

U.S. Army Engineer Research and Development Center

3909 Halls Ferry Road

Vicksburg, MS 39180-6199

Final report

Approved for public release; distribution is unlimited.

Prepared for U.S. Army Engineer Research and Development Center 3909 Halls Ferry Road

Vicksburg, MS 39180-6199

Under 6.1 Predictive Service Life Modeling of Concrete Deterioration Processes in Navigation Structures

Project Number 476923 


\section{Abstract}

This effort was undertaken as a part of the Service Life Modeling of Aging Navigation Structures 6.1 basic research program. Due to the increasing required service life of our infrastructure, additional evaluation tools are necessary to determine whether concrete mixture designs will meet the higher levels of design requirements and useful life. Additionally, these tools may be used as predictive damage analysis techniques to evaluate when critical damage will occur, and potential remedies are applied to bring structures back into operation parameters. This report features nondestructive test methods, coring and petrography, and service-life-based sorption measurements to evaluate two existing navigation structures. Concrete sections and samples were evaluated for damage using multiple methodologies, and comparisons were made to attempt to correlate damage depth and mechanisms with the sorption data.

DISCLAIMER: The contents of this report are not to be used for advertising, publication, or promotional purposes. Citation of trade names does not constitute an official endorsement or approval of the use of such commercial products. All product names and trademarks cited are the property of their respective owners. The findings of this report are not to be construed as an official Department of the Army position unless so designated by other authorized documents. 


\section{Contents}

Abstract.................................................................................................................................... if

Figures and Tables.....................................................................................................................

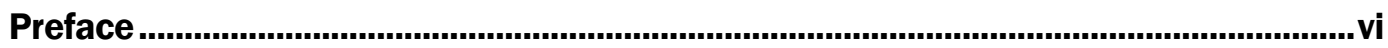

Unit Conversion Factors.................................................................................................vii

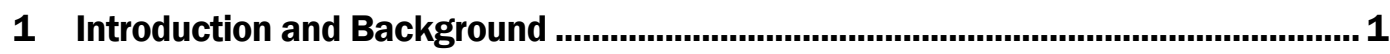

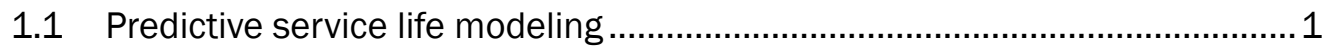

1.2 Concrete freeze-thaw deterioration .............................................................. 1

1.3 Concrete freeze-thaw modeling ............................................................. 2

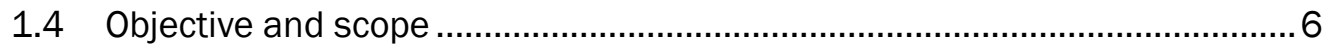

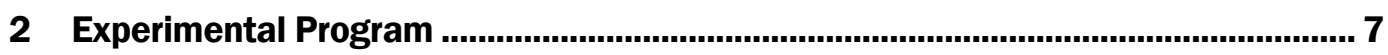

2.1 Sample collection and locations............................................................ 7

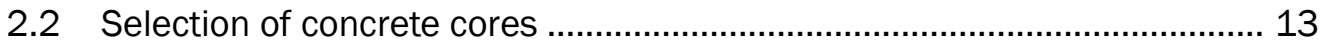

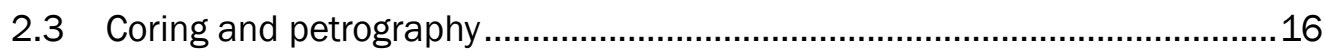

2.4 Laboratory sorption evaluations ............................................................ 17

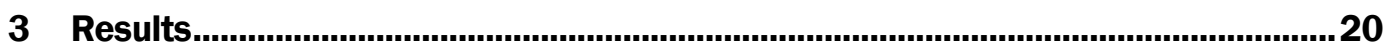

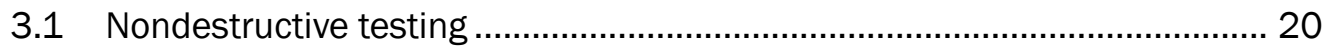

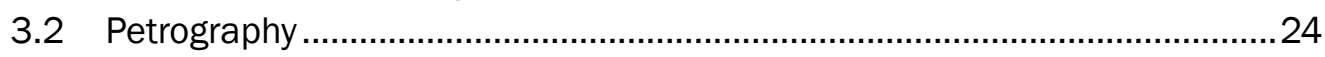

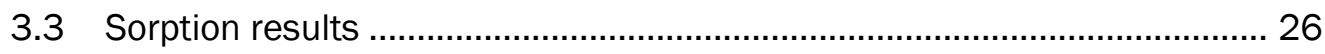

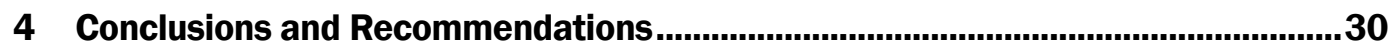

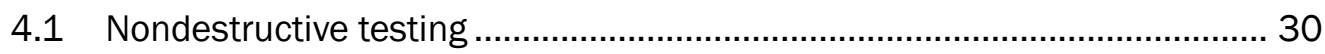

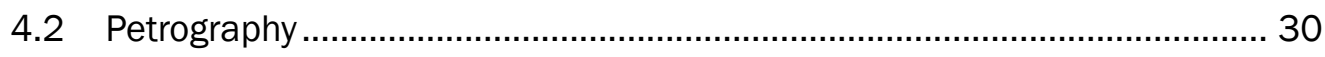

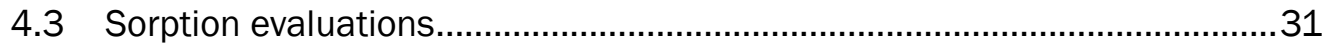

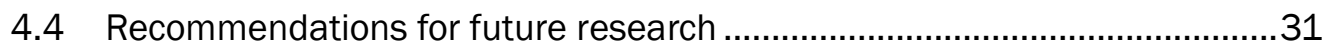

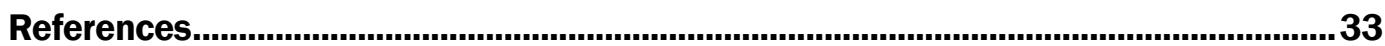

\section{Report Documentation Page}




\section{Figures and Tables}

\section{Figures}

Figure 1. Nick point time (Bentz et al. 2001)..................................................................... 4

Figure 2. CONCLIFE input parameters (Bentz 2000)...................................................... 5

Figure 3. CONCLIFE freeze/thaw output (Bentz 2000)..................................................... 5

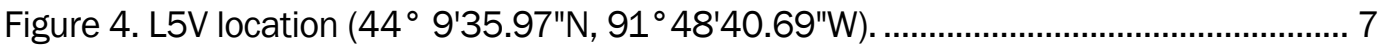

Figure 5. L5V section. ............................................................................................... 8

Figure 6. L5V grid labeling system (0-11 horizontal, 0-I vertical). ....................................... 8

Figure 7. L5H location $\left(44^{\circ} 9^{\prime} 38.55 " \mathrm{~N}, 91^{\circ} 48 ' 42.37 " \mathrm{~W}\right)$. .................................................... 9

Figure 8. L5H section.............................................................................................. 9

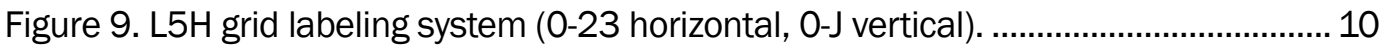

Figure 10. LSAFV location (4458'43.12"N, 93ำ14'47.37"W) ..................................... 10

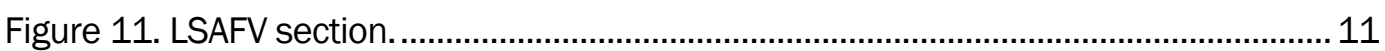

Figure 12. LSAFV grid labeling system (0-19 horizontal, 0-I vertical)................................. 11

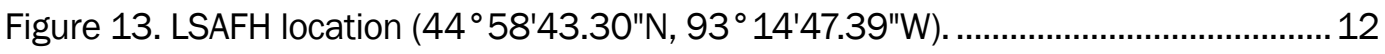

Figure 14. LSAFH section.............................................................................................. 12

Figure 15. LSAFH grid labeling system (0-15 horizontal, 0-M vertical)............................. 13

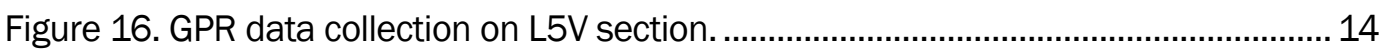

Figure 17. GPR data collection on L5H section. .......................................................... 14

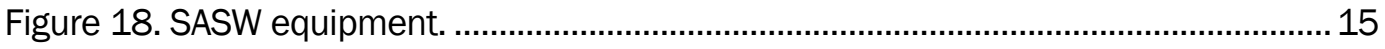

Figure 19. MIRA data collection and equipment.......................................................... 16

Figure 20. Puck with tape reservoir................................................................................. 18

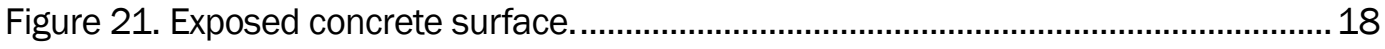

Figure 22. Silicon sealant. .......................................................................................... 19

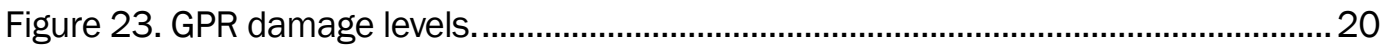

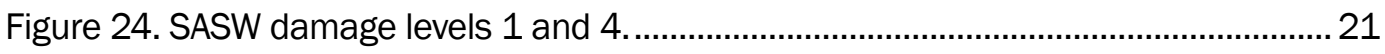

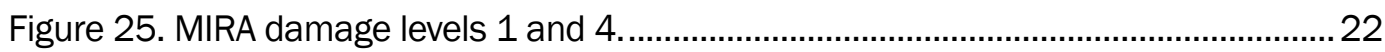

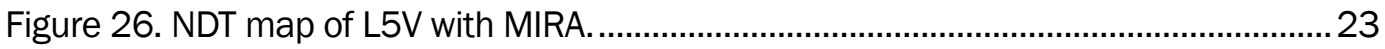

Figure 27. L5H as received. Right image was taken after wetting to better

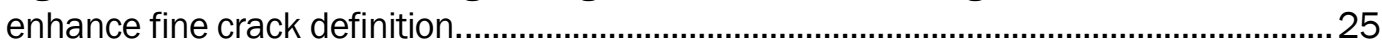

Figure 28. L5H as sectioned and polished. Blue arrow shows new concrete. Red arrows mark fractures. Yellow arrows mark saw cuts........................................................26

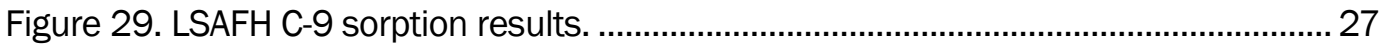

Figure 30. L5V F-5 sorption results. ........................................................................... 27

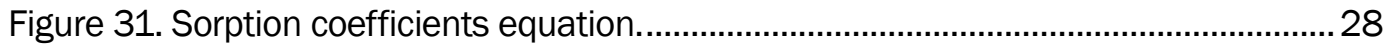

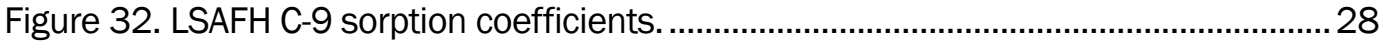

Figure 33. L5V F-5 sorption coefficients...................................................................... 28 


\section{Tables}

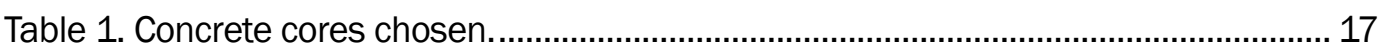

Table 2. Measured coefficients for model evaluations......................................................29 


\section{Preface}

This effort was undertaken as a part of the Service Life Modeling of Aging Navigation Structures 6.1 basic research program.

This work was performed by the Concrete and Materials Branch (GMC), Engineering Systems and Materials Division (GM), U.S. Army Engineer Research and Development Center, Geotechnical and Structures Laboratory (ERDC-GSL). At the time of publication, Mr. Christopher M. Moore was Chief, CEERD-GMC; Dr. Timothy Rushing was Acting Chief, CEERD-GM; and Mr. R. Nicholas Boone, CEERD-GZT, was the Technical Director for Force Projection and Maneuver Support. The Deputy Director of the ERDC-GSL was Mr. Charles W. Ertle II, and the Director was Mr. Bartley P. Durst.

COL Ivan P. Beckman was the Commander of ERDC, and Dr. David W. Pittman was the Director. 


\section{Unit Conversion Factors}

\begin{tabular}{|l|c|l|}
\hline Multiply & By & To Obtain \\
\hline cubic feet & 0.02831685 & cubic meters \\
\hline degrees Fahrenheit & $(\mathrm{F}-32) / 1.8$ & degrees Celsius \\
\hline feet & 0.3048 & meters \\
\hline gallons (US liquid) & $3.785412 \mathrm{E}-03$ & cubic meters \\
\hline inches & 0.0254 & meters \\
\hline square feet & 0.09290304 & square meters \\
\hline square inches & $6.4516 \mathrm{E}-04$ & square meters \\
\hline yards & 0.9144 & meters \\
\hline pounds & 0.453592 & kilograms \\
\hline
\end{tabular}




\section{Introduction and Background}

\subsection{Predictive service life modeling}

The current state of aging infrastructure in the United States has accelerated the need for accurate service-life design methodologies to predict failure rates of structures. Maintenance and repair efforts as well as prioritization of needs are critical as funding opportunities become increasingly limited. In order to meet these challenges, estimations of remaining usable service life are required.

This report contains testing and evaluation related to the U.S. Army Engineer Research and Development Center (ERDC) effort for predictive service-life modeling of concrete deterioration processes in navigation structures. The scope of the effort necessitates modeling multiple deterioration mechanisms such as corrosion of reinforcement, alkali-silica reactivity, and freeze-thaw resistance. Current knowledge gaps exist between the relationship of these mechanisms and the resulting damage effects over time on aging structures.

The first phase of this research effort focuses on rapid test methods to simulate aging in small-scale laboratory environments. Data from laboratory tests will be used as a basis for deterioration timelines. Physical field specimens will also be collected to evaluate and predict future deterioration of navigation structures based on the current distresses. Final products of the effort will be improved tools and updated testing parameters to more accurately predict when maintenance and repair activities will be necessary. This report contains the preliminary findings and experimental development for the freeze-thaw deterioration mechanism.

\subsection{Concrete freeze-thaw deterioration}

Concrete deterioration by freeze-thaw cycles can be caused by hydraulic pressures, freezing of gel water diffused into capillaries, and pressure differences caused by partial freezing and deicing salts. Therefore, understanding the presence and mechanisms associated with water ingress and movement in concrete is key in the measurement and prevention of freeze-thaw damage. 
Typical freeze-thaw testing is conducted in accordance with ASTM C666 (2015). However, this method may not give an accurate representation of what is considered failure in the field, and full testing can take up to six months. Due to this, various methodologies have been developed to investigate the damage mechanisms and effects on concrete service life. Magnetic resonance imaging (MRI) technology can be used to image the presence of water in concrete to better understand how freeze-thaw damage occurs (Prado et al. 1998). This can be particularly useful in cases in which the concrete or environmental condition is substantially different from normal cases to the point at which the formation of ice or water ingress is altered. For high-strength concretes with no air entrainment, Fluorescent Liquid Replacement (FLR) can be used to monitor crack formation (Jacobsen et al. 1995). In this method, water containing fluorescent dye is used to fill voids in concrete specimens, and then the specimens are inspected under ultraviolet light. Differences in patterns before and after freeze-thaw cycles can serve to illustrate how susceptible a particular mixture is to freeze-thaw damage.

\subsection{Concrete freeze-thaw modeling}

The basis of freeze-thaw modeling is largely constructed on a few main ideals. Water ingress into a non-saturated concrete is due to sorption driven by the capillary suction (Bentz et al. 1999). The consequences of this are localized stress differentials and the formation of micro-cracks. When the degree of saturation reaches $86 \%$ to $88 \%$, freeze-thaw damage is unpreventable even in air-entrained concrete mixtures (Li et al. 2012). Freeze-thaw cycles are unlikely to cause damage below this critical saturation level. Water and ion ingress through the concrete strongly depends on the paste structure, and, in most cases, the rate of deterioration is controlled by fracture strength (Basheer et al. 1996).

According to Alexander and Ballim (1993), any attempt at modeling must require three parts: (1) complete definition of the environment, (2) material characterization, and (3) appropriate tests methods. Bentz et al. (2001) concurs with this, stating the three parts as (1) characterization of appropriate materials, (2) adequate characterization of exposure environment, and (3) development of quantitative relationships. Multiple software programs have been developed in an attempt to take these factors and incorporate them in successfully modeling freeze-thaw occurrence and damage. 
Chen and Qiao (2015) attempted to correlate the data acquired from ASTM C666 to actual freeze-thaw cycles in the field to predict service life. This paper estimates that approximately 6.5 laboratory tests correspond to 1 field freeze-thaw cycle. The same level of failure as prescribed in ASTM C666 (40\% reduced relative dynamic modulus) is then applied to a regression equation used to model the actual service life. The authors caution that the relation of field tests to laboratory tests will differ based on location.

A model developed by the Massachusetts Institute of Technology (MIT) Concrete Sustainability Hub can simulate meso-scale water sorption and transport in 2-D microstructures that approximate the gel pore network (Zhou et al. 2015). This model operates under the assumption that damage is not primarily caused by the expansion of freezing water. The model indicates that water in the smallest pores may remain super-cooled during thawing and cause disjoining pressures or chemical reactions resulting in concrete damage. This assumption generally agrees with Li et al. (2012) that a critical saturation level, rather than solely the number of freezethaw cycles, determines damage.

Perhaps the most developed freeze-thaw modeling software, CONCLIFE, developed by the National Institute of Standards and Technology (NIST), functions using three submodels. The first, a finite difference onedimensional heat transfer model, is used to estimate surface temperature and time of wetness. Environmental data for this model are provided by the National Renewable Energy Laboratory (Marion and Urban 1995), or user-specified inputs can be imported.

The second model is based on the time-of-wetness data and measures sorption coefficients to predict service life using sulfate attack as the primary degradation mechanism. This model is based on work featured in Atkinson and Hearne (1990), but it uses sorption instead of diffusion as the main factor in sulfate ion transport.

The third model estimates service life based on freeze-thaw damage as the primary mechanism of degradation. The model is based on work by Fagerlund (1999) and considers failure is due to a slow saturation of air voids. This rate is equated to the sorption rate after the "nick point" time. Properties required for this model include porosity, air entrainment, critical saturation, sorption, and time-of-wetness data. Using the critical 
saturation value from Liu et al. (2012) and sorption measurements from Bentz et al. (2001) leaves the basic concrete properties and environmental data to be collected.

Models 1 and 3 of the CONCLIFE program should be able to estimate service life due to freeze-thaw damage within reasonable tolerances. Quantitative sorption coefficients before and after the "nick point" time can be calculated using ASTM C1583-13 (2013). This sorption coefficient difference is likely attributed to factors other than capillary forces and is shown in Figure 1. Example screenshots showing input parameters and a freeze-thaw damage analysis are shown in Figures 2 and 3, respectively.

Figure 1. Nick point time (Bentz et al. 2001).

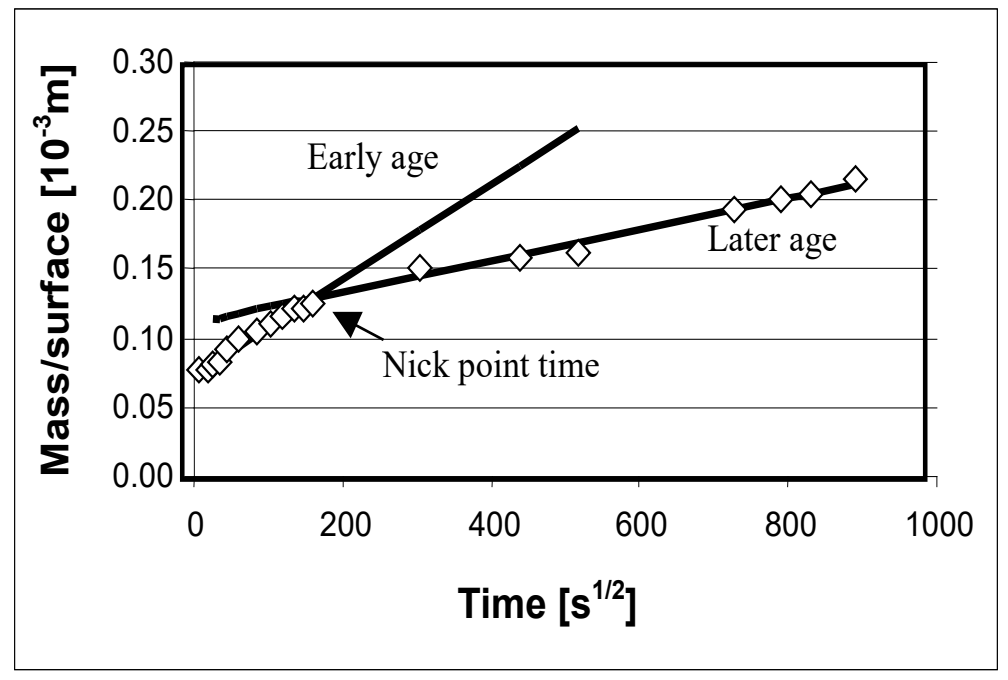


Figure 2. CONCLIFE input parameters (Bentz 2000).

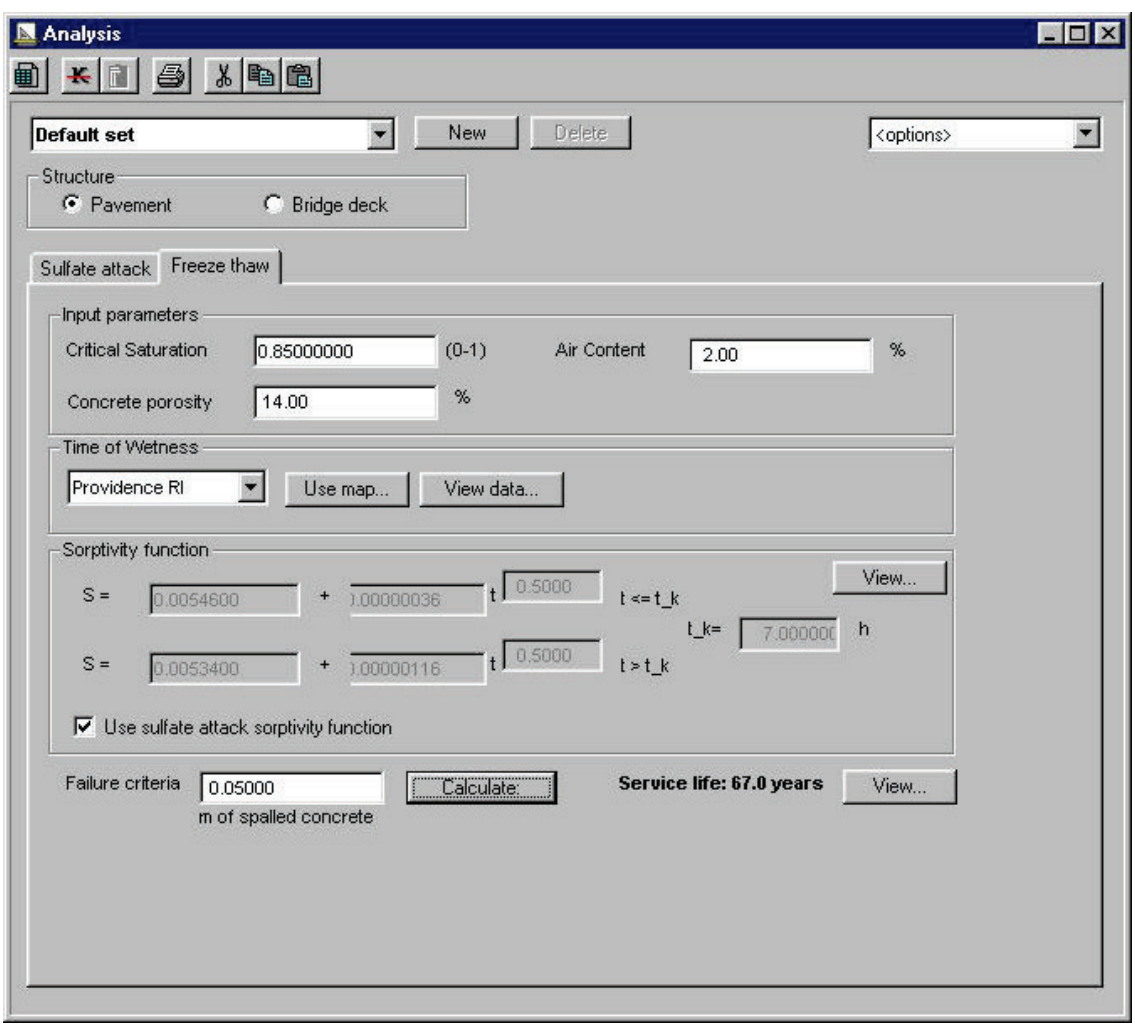

Figure 3. CONCLIFE freeze/thaw output (Bentz 2000).

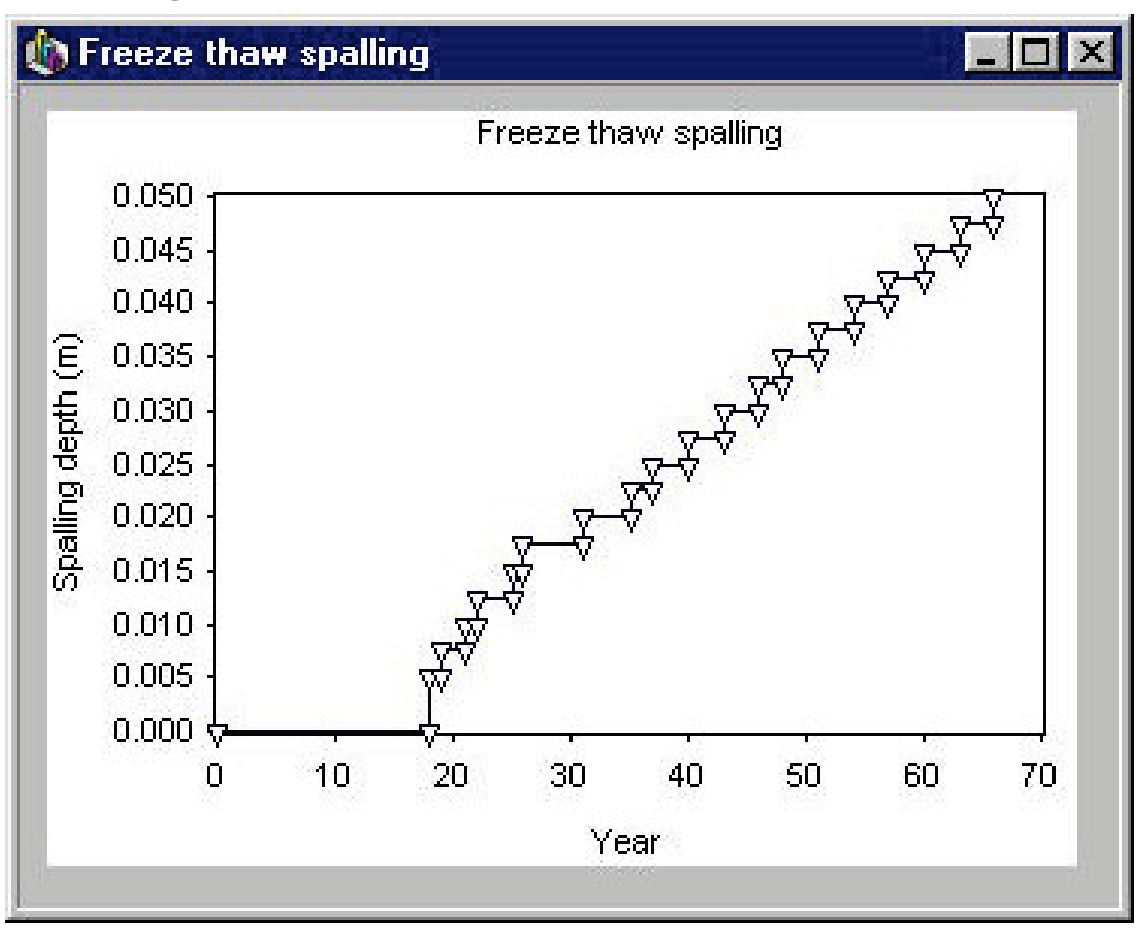


Despite the availability of the aforementioned models, none of the models found in the literature was capable of freeze/thaw deterioration prediction in navigational structures. This incapability is hypothesized to be due to a variety of factors. The authors themselves note that the models are newly developed and may not give accurate results for all scenarios, but due to the unique aspects of aging navigational structures, these discrepancies may be even more pronounced. Concrete thickness and the structures' proximity, and in some cases cyclically submerged nature, to rivers and lakes significantly alters inputs and greatly affects deterioration patterns.

\subsection{Objective and scope}

The overall objective of the research effort is to create or improve upon modeling capabilities to accurately predict material deterioration over time in aging navigation infrastructure. This should allow for a shift from reactive maintenance to preventative maintenance, which could reduce costs and increase infrastructure usability. Due to the size of the overall effort, this report will focus only on the freeze-thaw deterioration mechanism. The remainder of this report details the laboratory testing and field studies associated with this mechanism. 


\section{Experimental Program}

\subsection{Sample collection and locations}

Field evaluations and collection of samples were conducted by Braun Intertec Corporation under the supervision of USACE personnel or directly by USACE. Locations were chosen based on large amounts of perceived susceptibility to freezing and thawing. Structures chosen for this analysis were the Lower St. Anthony Falls Lock and Dam (LSAF) located in Minneapolis, MN, and the Lock and Dam No. 5 (L5) located in Minnesota City, MN. Four sites, each of which contained a vertical and a horizontal section, were chosen for evaluation.

The $\mathrm{L}_{5}$ vertical section ( $\mathrm{L}_{5} \mathrm{~V}$ ) was chosen on the I-Wall of the chamber at Panel 13. This section is located in what is considered the "splash zone," the area of the vertical lock wall in which the concrete is submerged at the high water level and unsubmerged at the low water level for normal lock operations. The location of section $\mathrm{L}_{5} \mathrm{~V}$ is shown in Figures 4, 5, and 6. Each section was marked with spray paint and given a grid system for labeling of cores and marking deterioration. Each point on the grid system is $1 \mathrm{ft}$ from adjacent points.

Figure 4. L5V location (44 9'35.97"N, 9148'40.69"W).

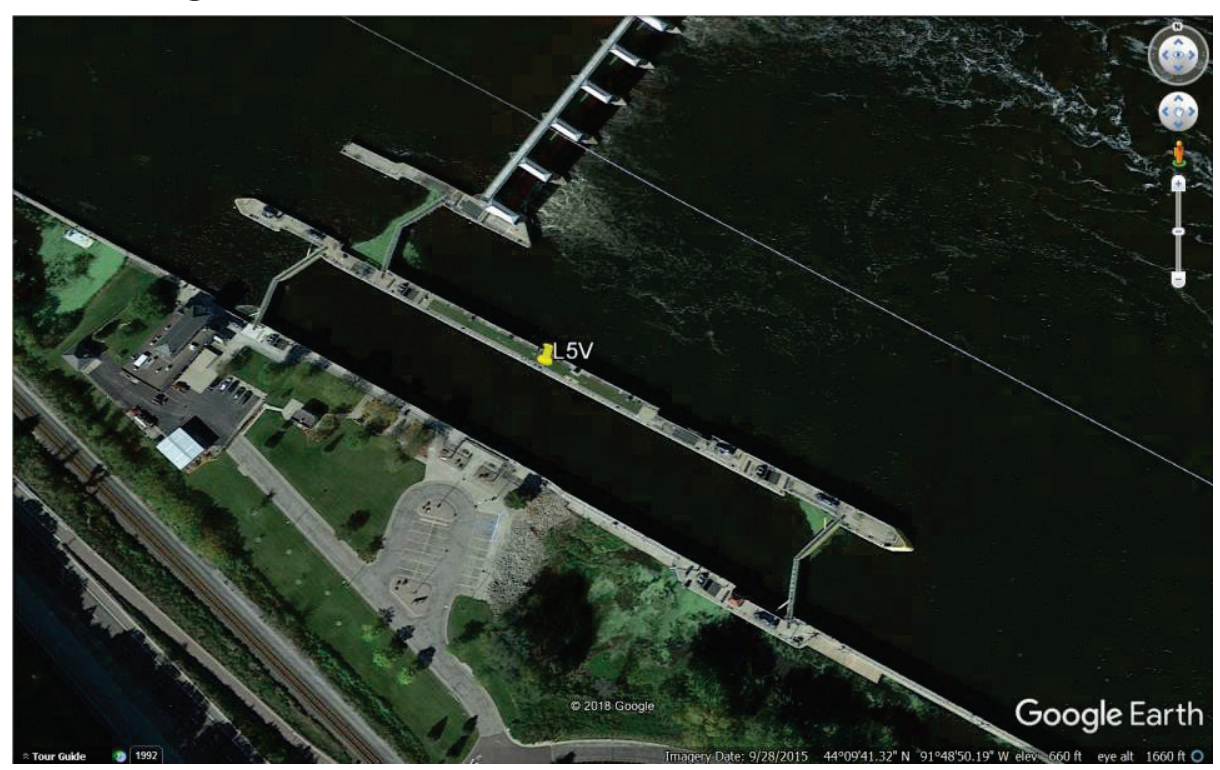


Figure 5. L5V section.

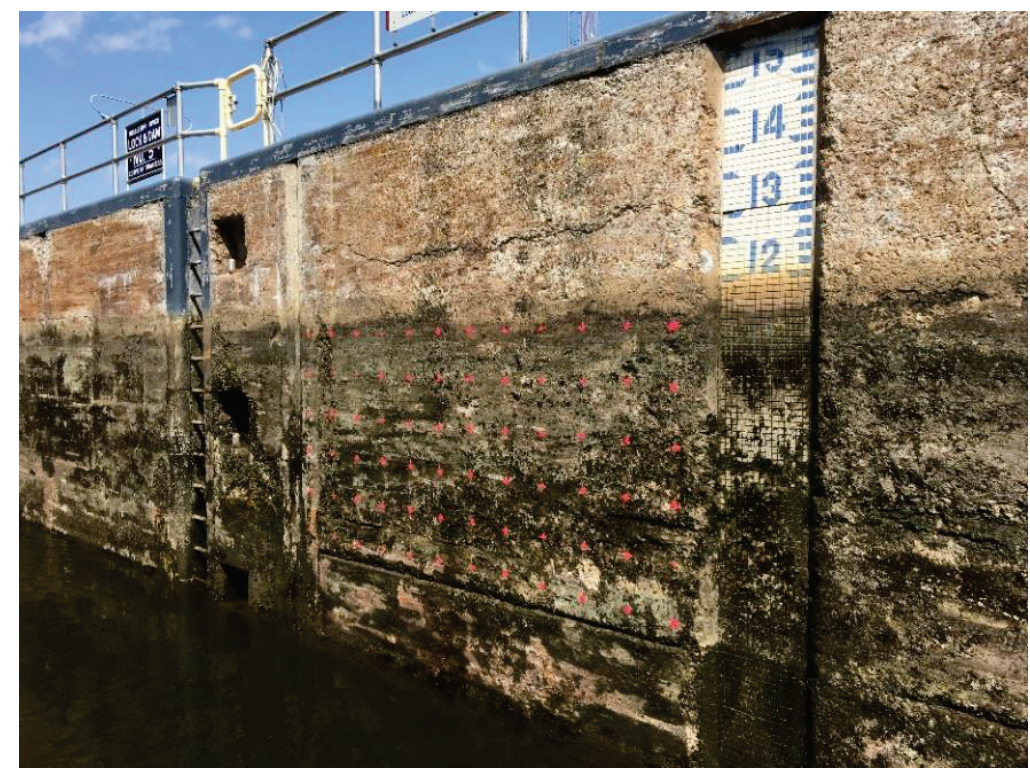

Figure 6. L5V grid labeling system (0-11 horizontal, 0-I vertical).

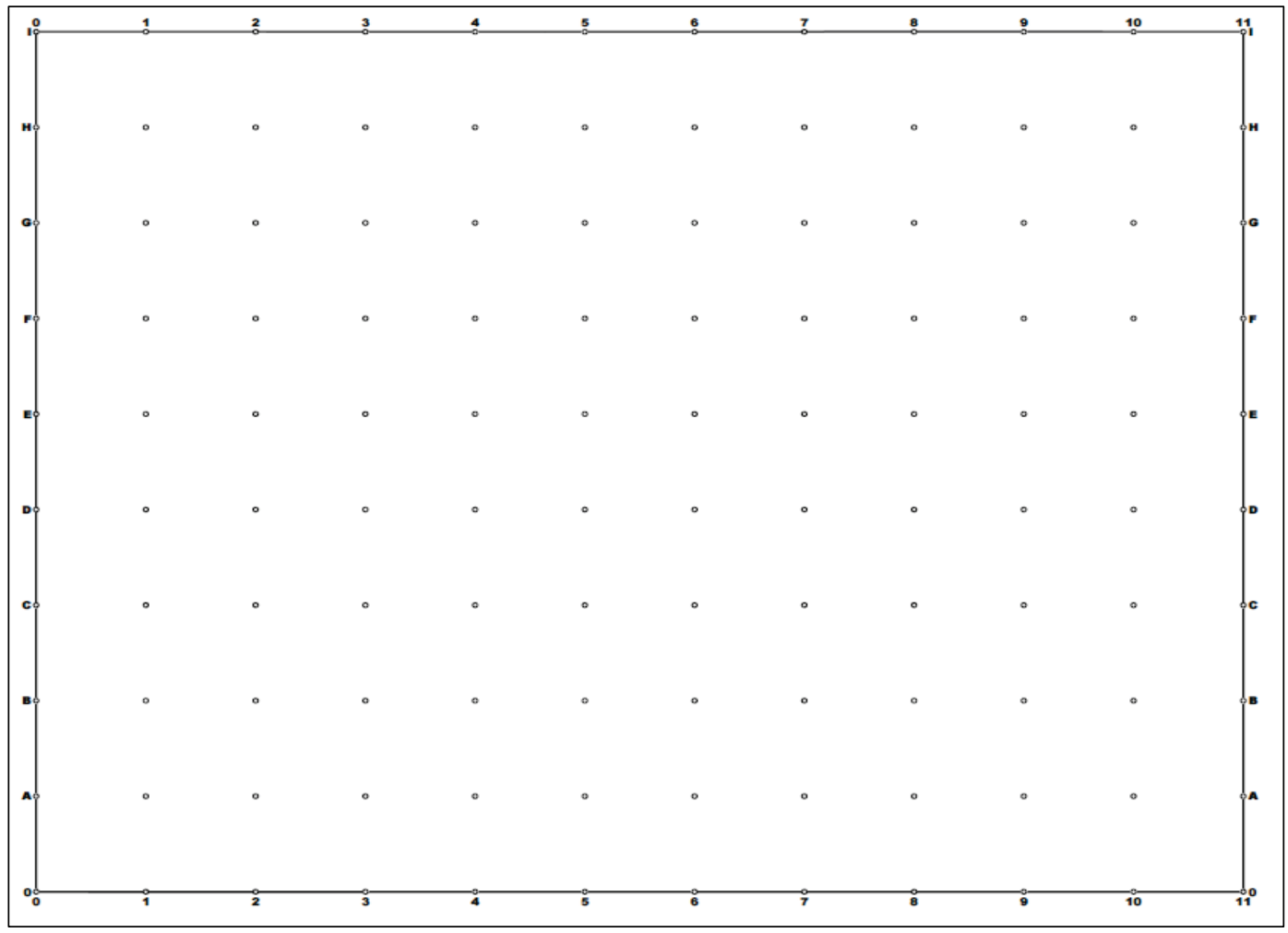

The $\mathrm{L}_{5}$ horizontal section $\left(\mathrm{L}_{5} \mathrm{H}\right)$ was chosen on the deck of the river wall, monolith 5. This section contained several patches, joints, and visible spalls. Figures 7,8 , and 9 serve to illustrate this section. 
Figure 7. L5H location $\left(44^{\circ} 9^{\prime} 38.55^{\prime \prime} \mathrm{N}, 91^{\circ} 48^{\prime} 42.37^{\prime \prime} \mathrm{W}\right)$.

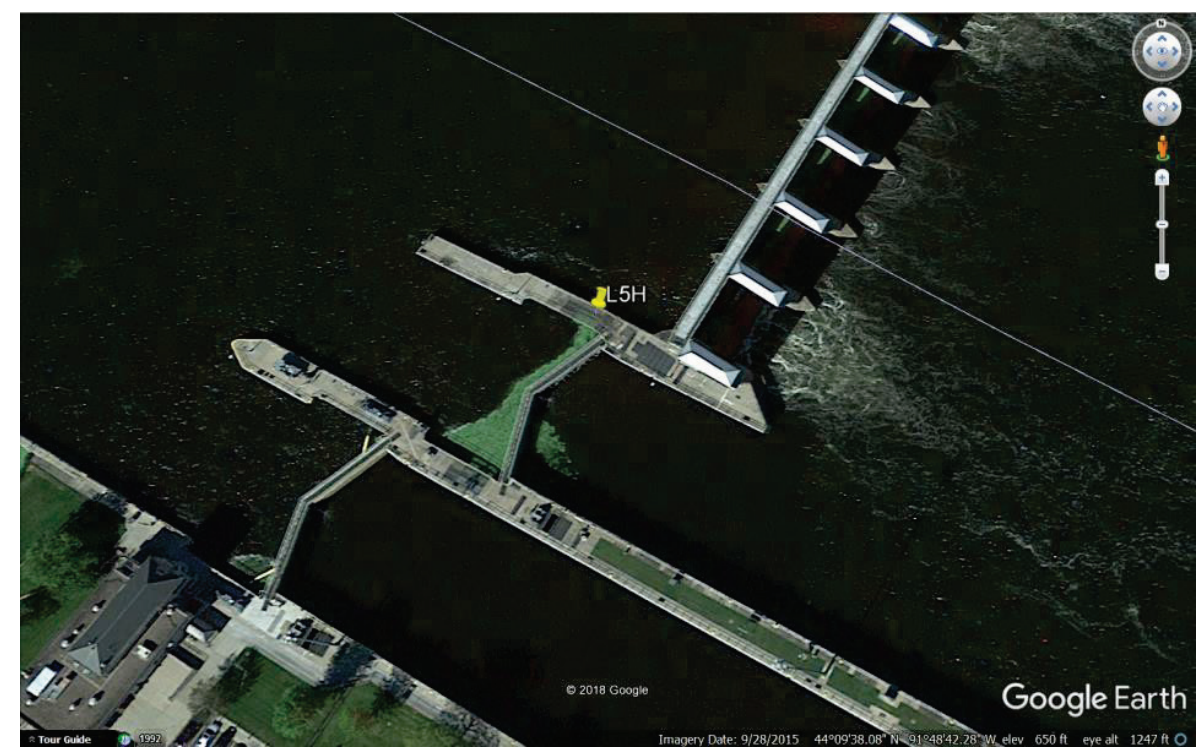

Figure 8. L5H section.

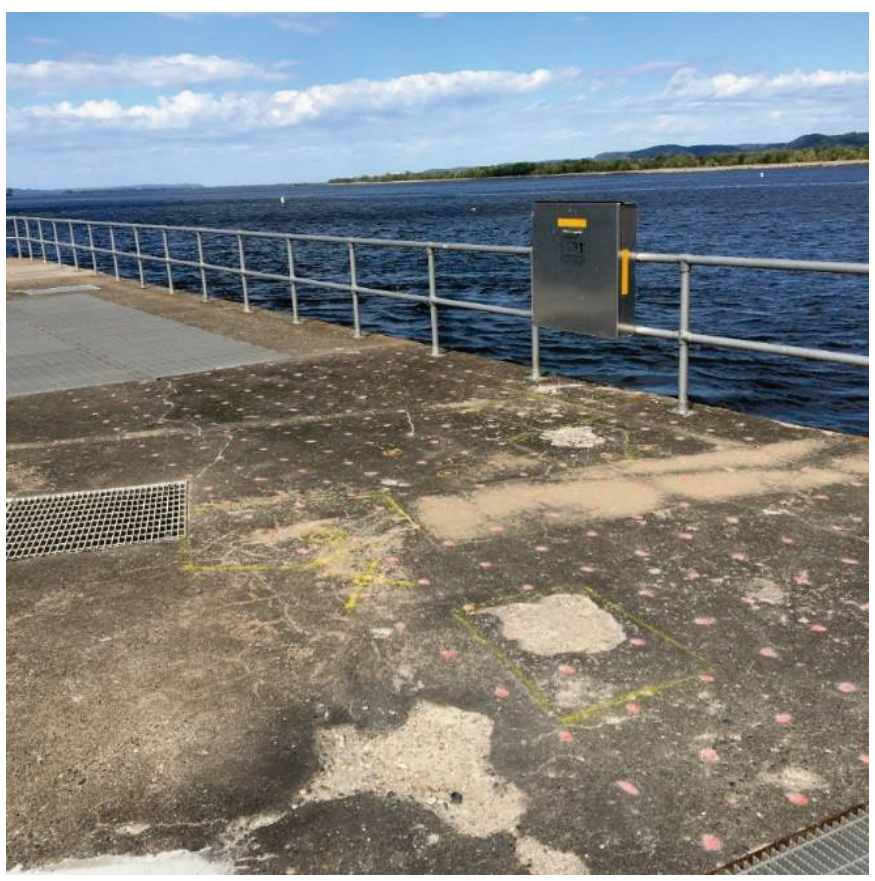


Figure 9. L5H grid labeling system (0-23 horizontal, 0-J vertical).

\begin{tabular}{|c|c|c|c|c|c|c|c|c|c|c|c|c|c|c|c|c|c|c|c|c|c|c|c|}
\hline دْ & 1 & 2 & $\Omega_{-3}^{3}$ & 4 & 5 & $\underbrace{6}_{-\infty}$ & 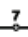 & a & ـ & 10 & 11 & 12 & 13 & 14 & $\underbrace{15}$ & $\underbrace{18}$ & 17 & 18 & 19 & 20 & 21 & 22 & 23. \\
\hline 1 & 。 & 。 & $\circ$ & 。 & 。 & 。 & 。 & 。 & 。 & $\circ$ & 。 & 。 & $\circ$ & 。 & ○ & $\circ$ & 。 & ○ & ○ & 。 & 。 & 。 & 1 \\
\hline Ho & 。 & 。 & 。 & 。 & 。 & 。 & 。 & 。 & 0 & 。 & 。 & $\circ$ & $\circ$ & $\circ$ & $\circ$ & 0 & 。 & $\circ$ & ○ & 。 & $\circ$ & ○ & $\mathrm{H}$ \\
\hline of & $\circ$ & $\circ$ & $\circ$ & $\circ$ & 。 & $\circ$ & ० & 。 & $\circ$ & $\circ$ & $\circ$ & $\circ$ & $\circ$ & ○ & $\circ$ & $\circ$ & 。 & ○ & $\circ$ & ○ & ○ & $\circ$ & e \\
\hline E & $\circ$ & $\circ$ & $\circ$ & $\circ$ & $\circ$ & $\circ$ & ○ & 。 & $\circ$ & $\circ$ & 。 & $\circ$ & $\circ$ & 。 & $\circ$ & 。 & 。 & ○ & 。 & 。 & 。 & $\circ$ & $\mathrm{E}$ \\
\hline of & $\circ$ & 。 & $\circ$ & - & $\circ$ & 。 & - & 。 & 。 & 。 & $\circ$ & 。 & ○ & 。 & - & 。 & 。 & - & 。 & 0 & 0 & 。 & 0 \\
\hline$c$ & 。 & $\circ$ & $\circ$ & 。 & $\circ$ & 。 & - & 。 & $\circ$ & $\circ$ & 。 & 。 & 。 & 。 & $\circ$ & $\circ$ & 。 & 。 & 。 & 。 & 。 & 。 & $c$ \\
\hline of & 1 & 2 & 3 & 4 & 8 & 8 & 7 & 8 & 9 & 10 & 11 & 12 & 13 & 14 & 18 & 16 & 17 & 18 & 19 & 20 & 21 & 22 & 230 \\
\hline
\end{tabular}

The LSAF vertical section (LSAFV) was chosen on the I-Wall at Panel I10. Similar to the $\mathrm{L}_{5} \mathrm{~V}$ section, this section is also located in the splash zone. The location was observed to have portions of visible deterioration. Figures 10, 11, and 12 show the LSAFV section.

Figure 10. LSAFV location $\left(44^{\circ} 58^{\prime} 43.12^{\prime \prime} \mathrm{N}, 93^{\circ} 144^{\prime} 47.37^{\prime \prime} \mathrm{W}\right)$.

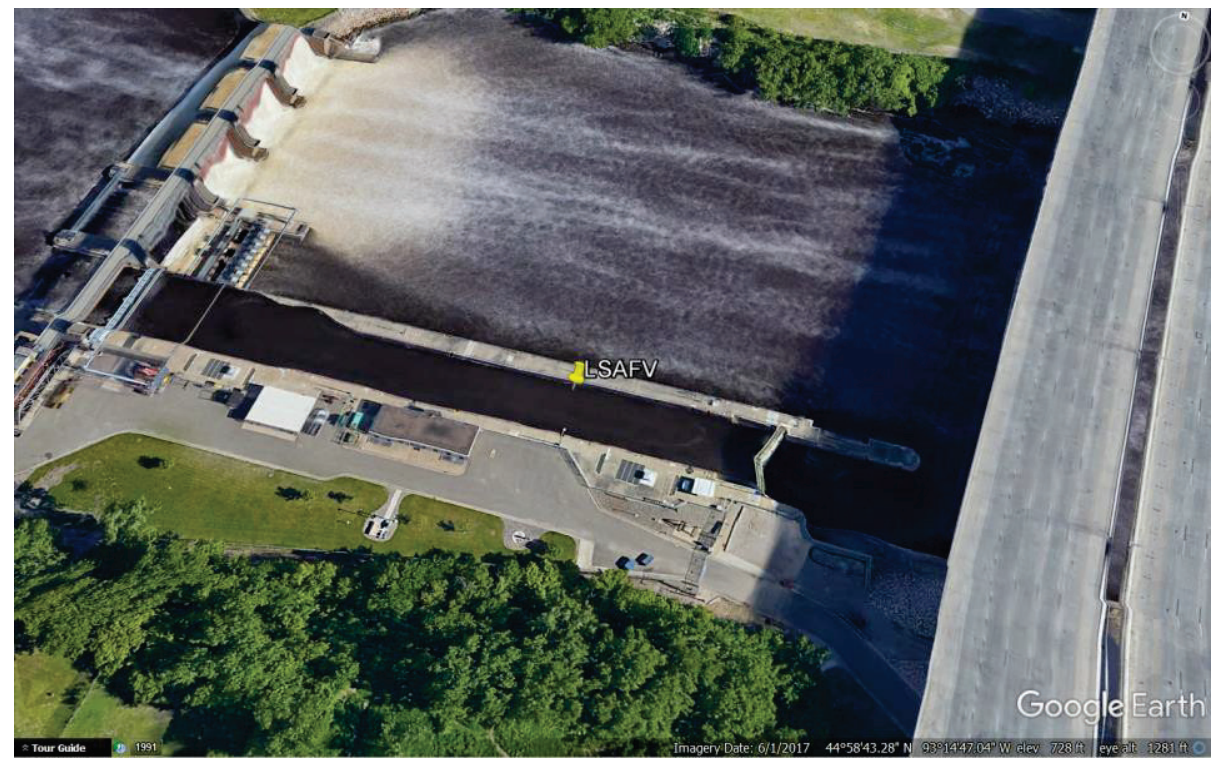


Figure 11. LSAFV section.

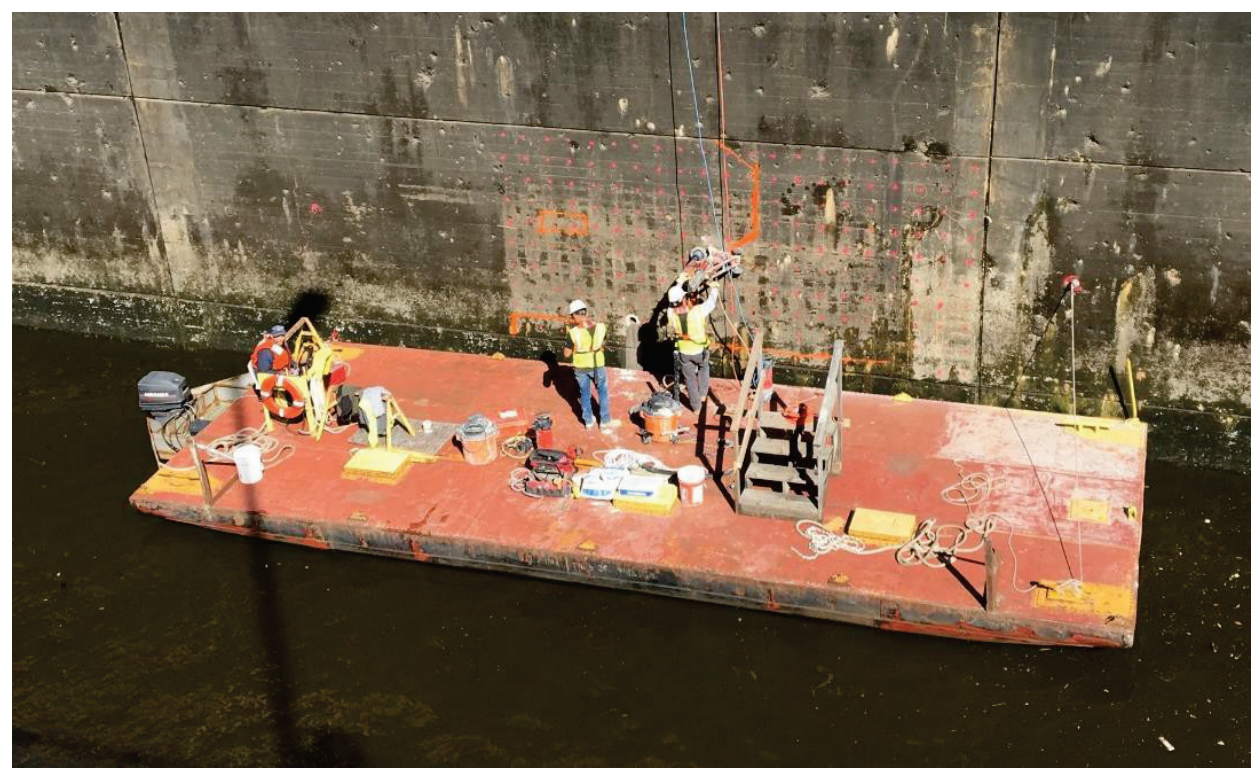

Figure 12. LSAFV grid labeling system (0-19 horizontal, 0-I vertical).

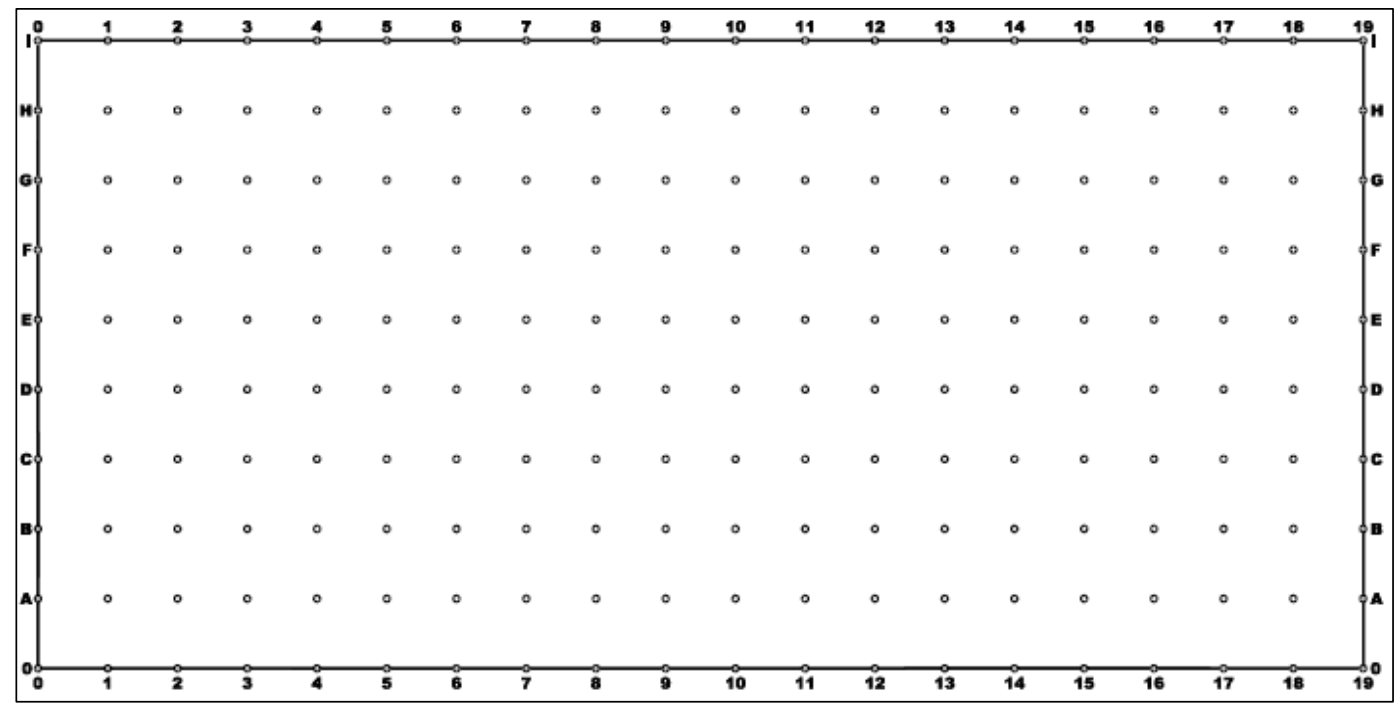

The LSAF horizontal section (LSAFH) was chosen from the deck of the IWall at Panels I10 and I11. This section included a monolith joint associated with a large amount of perceived deterioration. LSAFH is shown in Figures 13, 14, and 15. 
Figure 13. LSAFH location $\left(44^{\circ} 58^{\prime} 43.30 " \mathrm{~N}, 93^{\circ} 14^{\prime} 47.39 " \mathrm{~W}\right)$.

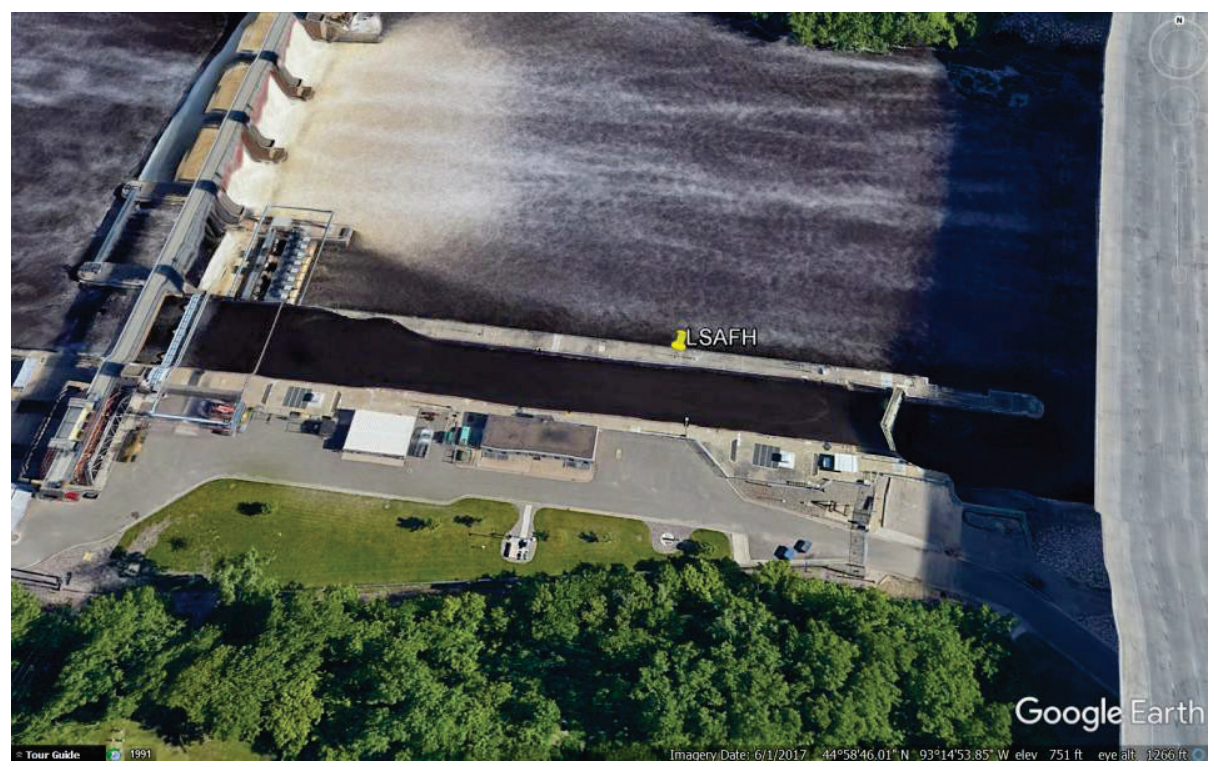

Figure 14. LSAFH section.

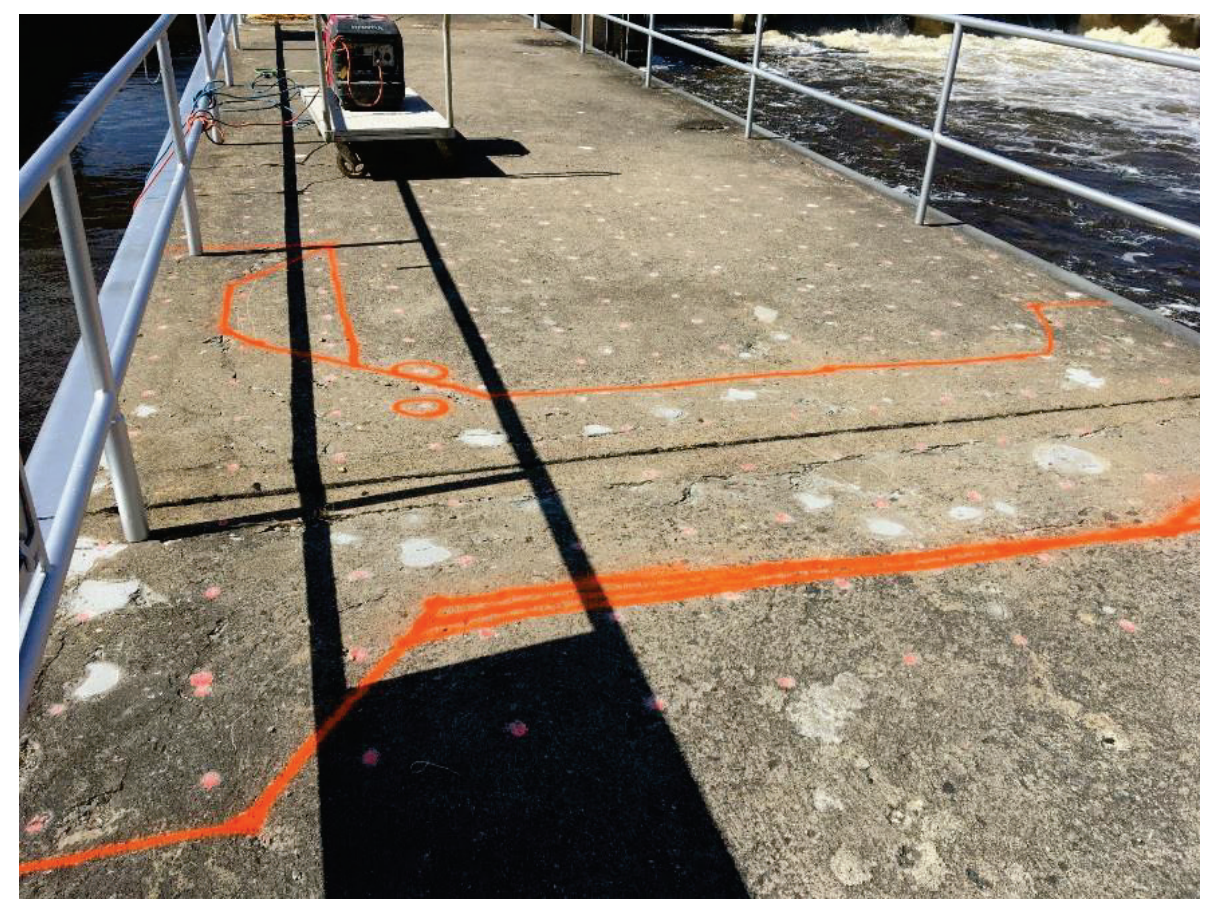


Figure 15. LSAFH grid labeling system (0-15 horizontal, 0-M vertical).

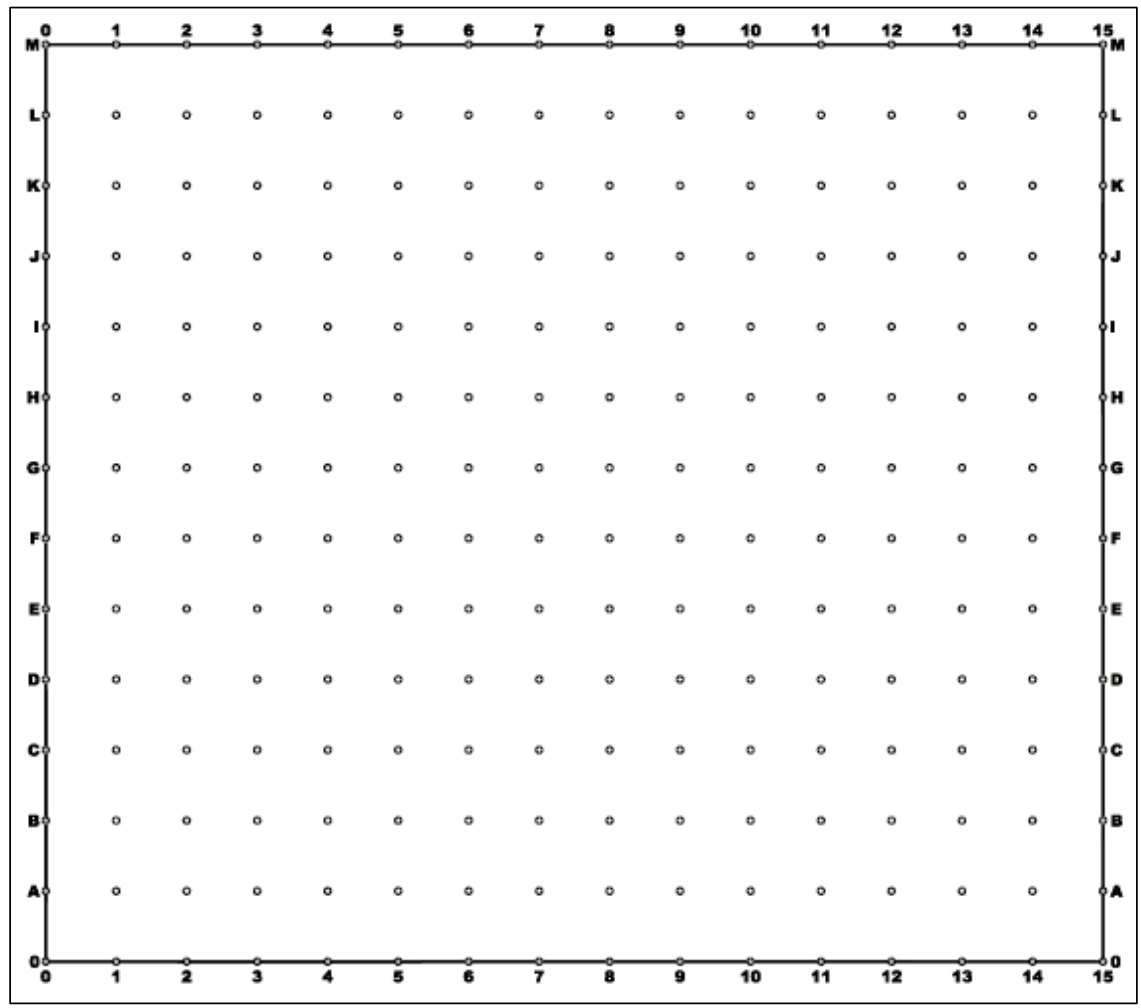

\subsection{Selection of concrete cores}

In each of the four described grid sections, a suite of nondestructive tests (NDT) was conducted to determine the most appropriate locations for coring. The NDT devices used included Ground Penetrating Radar (GPR), Spectral Analysis of Surface Waves (SASW), Ultrasonic Shear-Wave Tomography (MIRA), and sounding.

Two GPR systems were used during testing; both were Geophysical Survey Systems Inc. Structure Scan platforms using either a $1.6 \mathrm{GHz}$ or $2.6 \mathrm{Ghz}$ antenna. GPR systems function by transmitting electromagnetic pulses into the concrete and measuring the reflected response to allow for variations in materials and densities to be observed and recorded. GPR testing was conducted at the manufacturer's suggested 10 scans per in. and a depth of 16 in. GPR lines were collected in both "x" (horizontal) and "y" (vertical) directions with respect to the testing grids, resulting in a total of 234 GPR data lines or 3,00o linear $\mathrm{ft}$ of data. Figures 16 and 17 show GPR data collection. 
Figure 16. GPR data collection on L5V section.

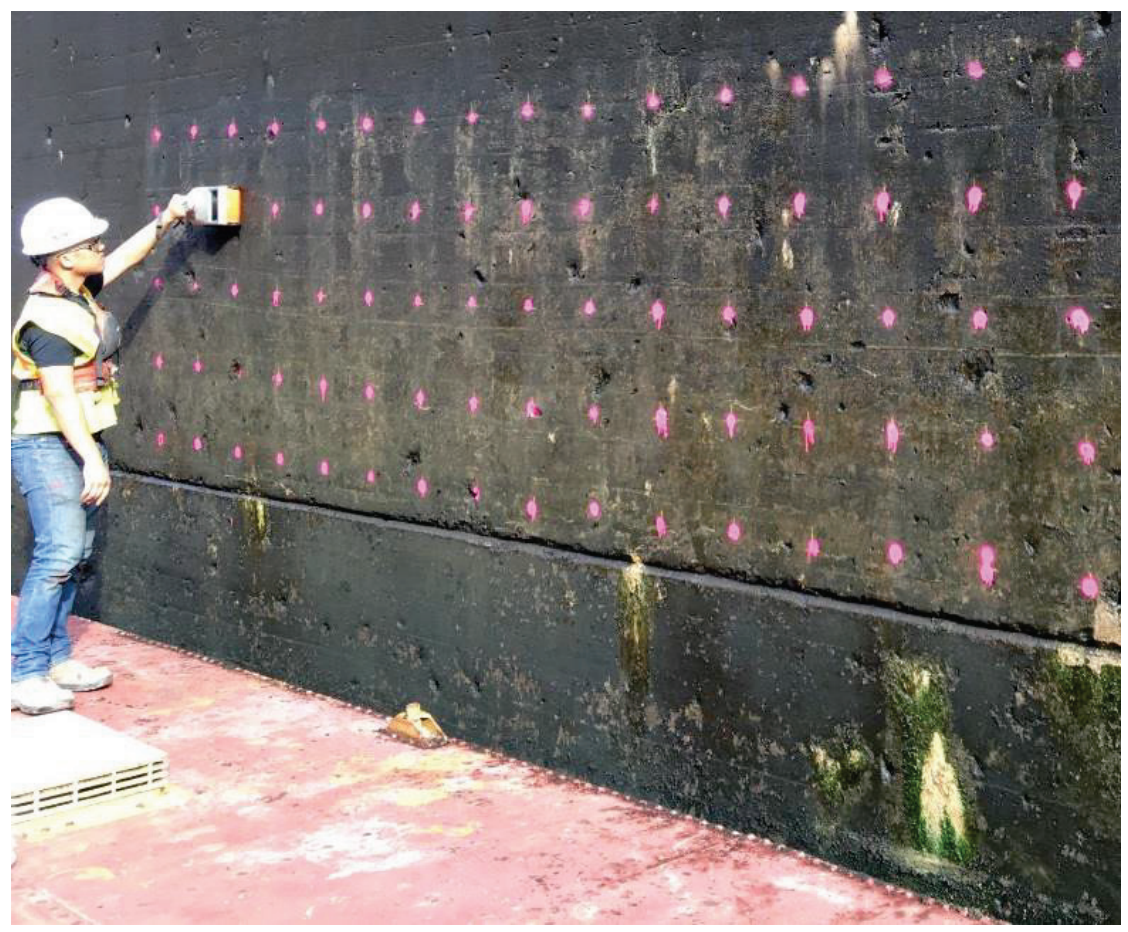

Figure 17. GPR data collection on L5H section.

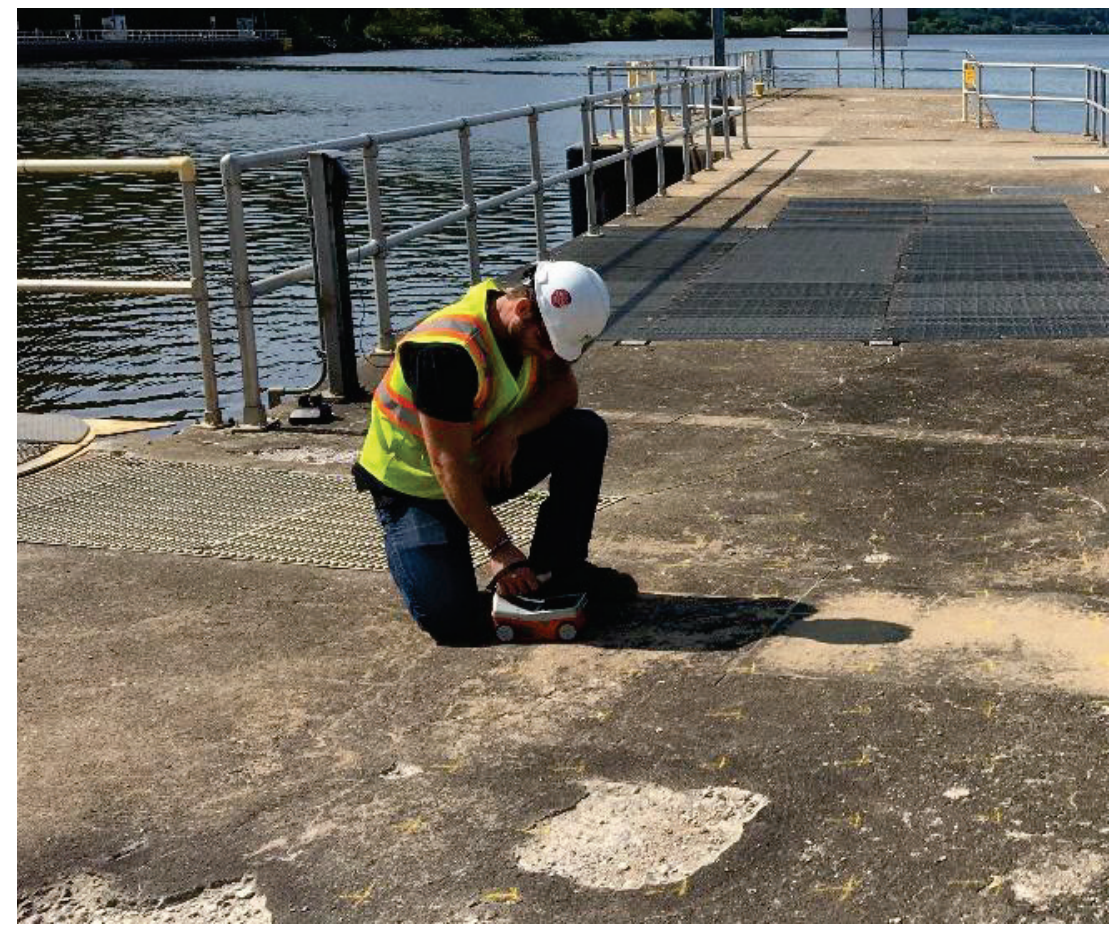

SASW testing consisted of a surface impact device and a collection device at a certain distance to measure wave velocities through the media. For this project, an Olson Instruments SASW-S system was used at a sensor 
spacing distance of 12 in. Data were collected in a left-to-right orientation so that when the impact was tested at point 1 , the collection sensor would be at point 2 as per the grid layout. The final point in each line would naturally cause the data collected to be located outside of the grid. Three "strikes" of the impactor were measured at each location. Over 2,100 SASW data points were collected. SASW equipment is shown in Figure 18.

Figure 18. SASW equipment.

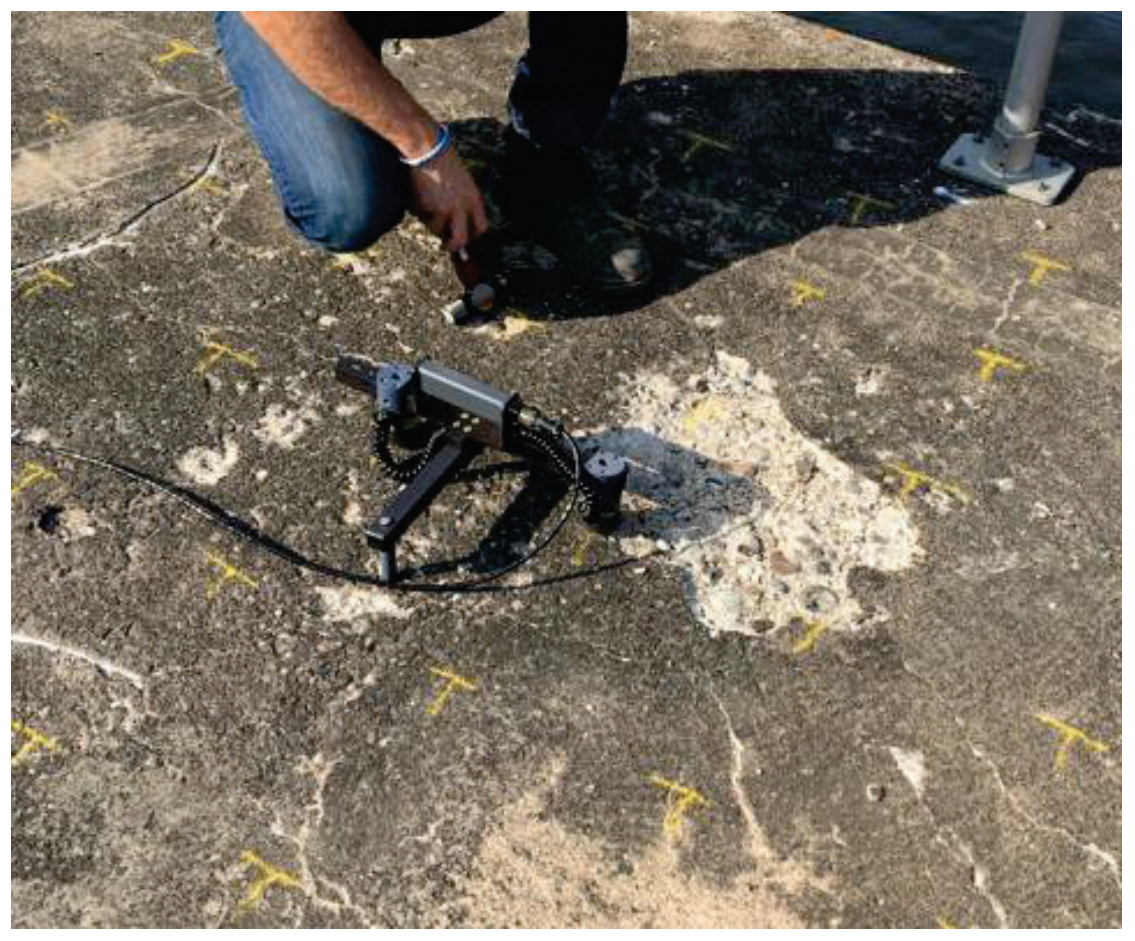

MIRA testing utilizes a low-frequency ultrasonic system designed for concrete evaluation. An array of contact points produces elastic waves that are collected paired measurements, which allow for the interpretation of changes in the concrete subsurface. For this project, a MIRA-5000 \#d Shear Wave Tomography System was used. Three data points were collected for each location in the grid test layout: directly on the point, slightly offset left, and slightly offset right. Approximately 2,500 data points were collected with the MIRA system. Figure 19 shows MIRA data collection. 
Figure 19. MIRA data collection and equipment.

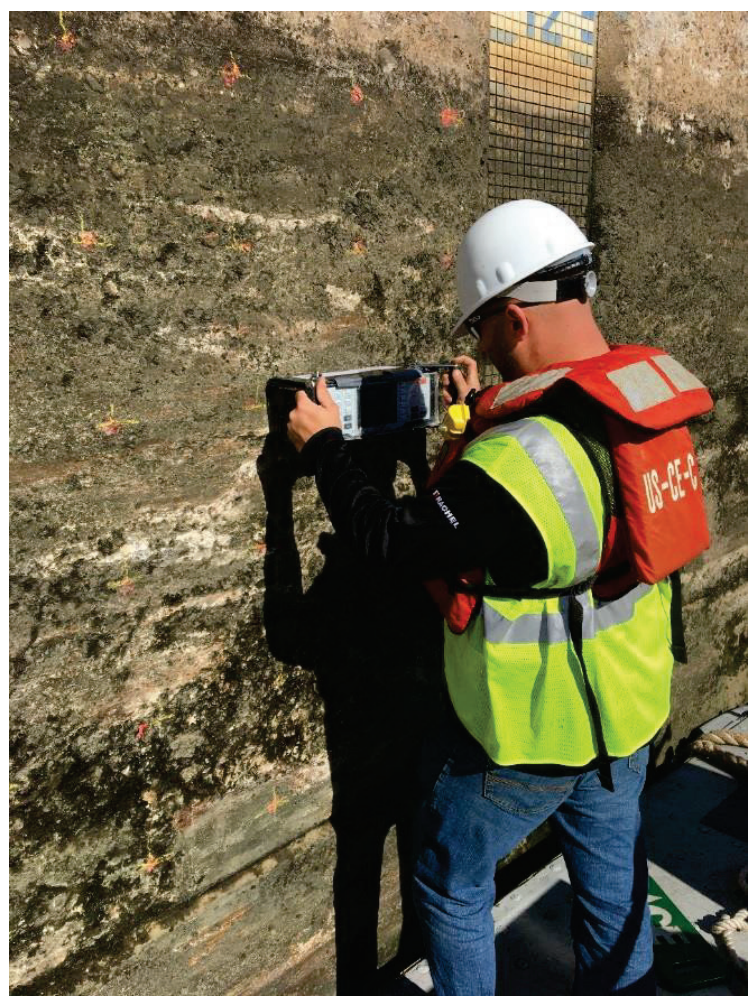

The final technique that utilized sounding was performed by striking the concrete and interpreting the resulting sound. An experienced sounding technician can interpret the results based on sound if the concrete is likely damaged. Potentially damaged areas were marked and recorded.

\subsection{Coring and petrography}

After the completion and evaluation of the NDT data, locations for coring were chosen. The locations were chosen in order to collect a broad range of cores based on NDT data. Eight cores each were chosen for $\mathrm{L}_{5} \mathrm{~V}, \mathrm{~L} 5 \mathrm{H}$, and LSAFH. Ten cores were chosen for LSAFV. Table 1 lists the location and status of each core. Thirty-four cores in total were obtained for the project. Cores were extracted using a 4-in. inside-diameter barrel to a depth of 16 in. in general accordance with ASTM C42M (2018a) and patched in accordance with ASTM C1107M (2017). 
Table 1. Concrete cores chosen.

\begin{tabular}{|c|c|c|c|c|c|c|c|}
\hline \multicolumn{2}{|r|}{$\mathrm{L} 5 \mathrm{H}$} & \multicolumn{2}{|r|}{ L5V } & \multicolumn{2}{|r|}{ LSAFH } & \multicolumn{2}{|r|}{ LSAFV } \\
\hline $\begin{array}{l}0.5, \\
14.6\end{array}$ & souding bad & A, 2 & souding bad & C, 9 & sounding good & $\mathrm{A}, 5.4$ & extra good \\
\hline $\begin{array}{l}0.5, \\
16.5 \\
\end{array}$ & $\begin{array}{l}\text { souding } \\
\text { good }\end{array}$ & B, 3 & sounding good & $\begin{array}{l}\mathrm{C} \\
10 \\
\end{array}$ & souding bad & D. $4,8.6$ & sasw good \\
\hline D, 11 & mira good & B, 10 & sasw bad & $\begin{array}{l}\text { C, } \\
13\end{array}$ & sasw bad & $\begin{array}{l}\text { D.4, } \\
10.9\end{array}$ & sasw bad \\
\hline D, 13 & mira bad & C, 9 & sasw good & $\begin{array}{l}\mathrm{C} \\
14\end{array}$ & sasw bad & E.3, 2.5 & sounding bad \\
\hline$F, 21$ & extra good & $\begin{array}{l}\text { D.5, } \\
0.2 \\
\end{array}$ & extra bad & $\mathrm{H}, 9$ & mira good & F.3, 2.6 & souding good \\
\hline $\mathrm{G}, 14$ & sasw bad & $\mathrm{E}, 0.8$ & mira bad & $\begin{array}{l}\mathrm{H}, \\
10\end{array}$ & mira bad & $\begin{array}{l}F .5, \\
17.5 \\
\end{array}$ & $\begin{array}{c}\text { all ndt really } \\
\text { bad }\end{array}$ \\
\hline $\mathrm{H}, 14$ & sasw good & $\mathrm{E}, 2$ & mira good & $\mathrm{K}, 8$ & extra good & $\begin{array}{l}\text { G.5, } \\
17.5 \\
\end{array}$ & extra bad \\
\hline $\mathrm{J}, 17$ & extra bad & $\mathrm{F}, 5$ & extra good & $\mathrm{L}, 9$ & extra bad & G.6, 11 & mira good \\
\hline & & & & & & G.6, 13 & mira int. \\
\hline & & & & & & $\begin{array}{l}\text { G.7, } \\
13.8 \\
\end{array}$ & mira bad \\
\hline
\end{tabular}

Each core sample was labeled and photographed as received and evaluated for depths of cracks, detachments, freeze-thaw damage, and ASR damage. After preliminary testing, a full petrographic analysis conducted in accordance with ASTM C856 (2018b) was performed on one core from each test location. In addition to this testing, two core samples were sent to ERDC in Vicksburg, MS, for sorption testing for use in fitting a damage model for the existing structure.

\subsection{Laboratory sorption evaluations}

Concrete cores tested at ERDC were evaluated for sorption based on methods described in Bentz et al. (2001). Cores were sliced into "pucks" of 4 -in. depth and were surrounded by a nonpermeable tape in order to form a reservoir of water on top of the sample. Construction-grade silicon sealant was used to seal the tape to the surface of the puck. Figures 20, 21, and 22 show the puck with the reservoir prior to testing. The reservoir was designed to hold approximately 0.5 in. of water above the puck.

To test the reservoir, water was first filled, then emptied, and the surface patted dry to achieve a saturated surface dry condition. An initial mass measurement was then taken. The reservoir was refilled and the specimens allowed to sit at room temperature on a laboratory bench until the next measurement at which time the technique was repeated. Specimens were monitored and measurements recorded for a minimum of five consecutive days. 
Figure 20. Puck with tape reservoir.

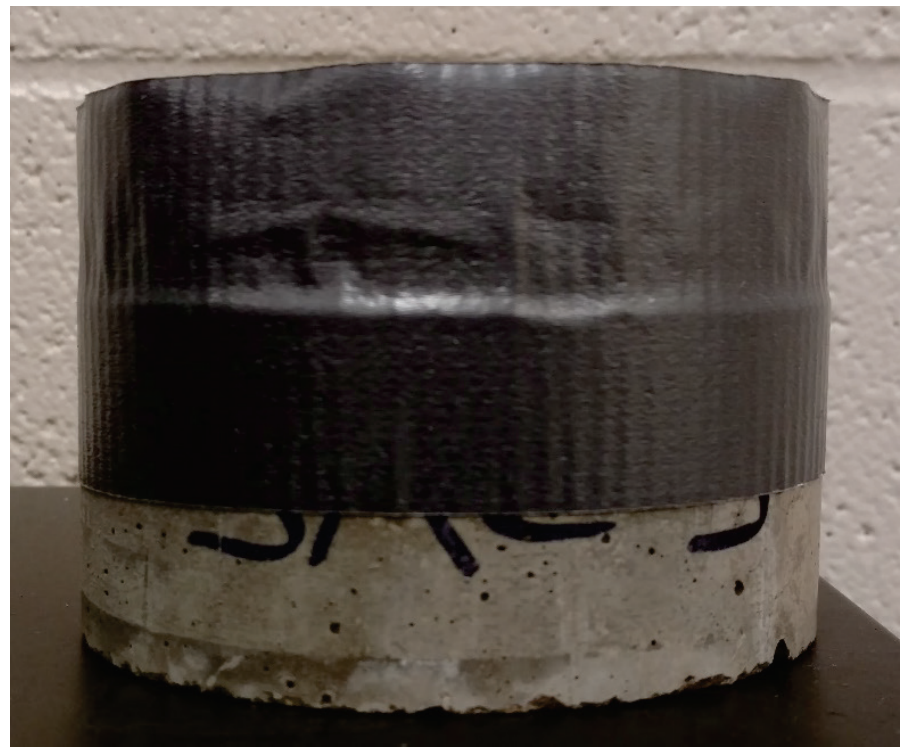

Figure 21. Exposed concrete surface.

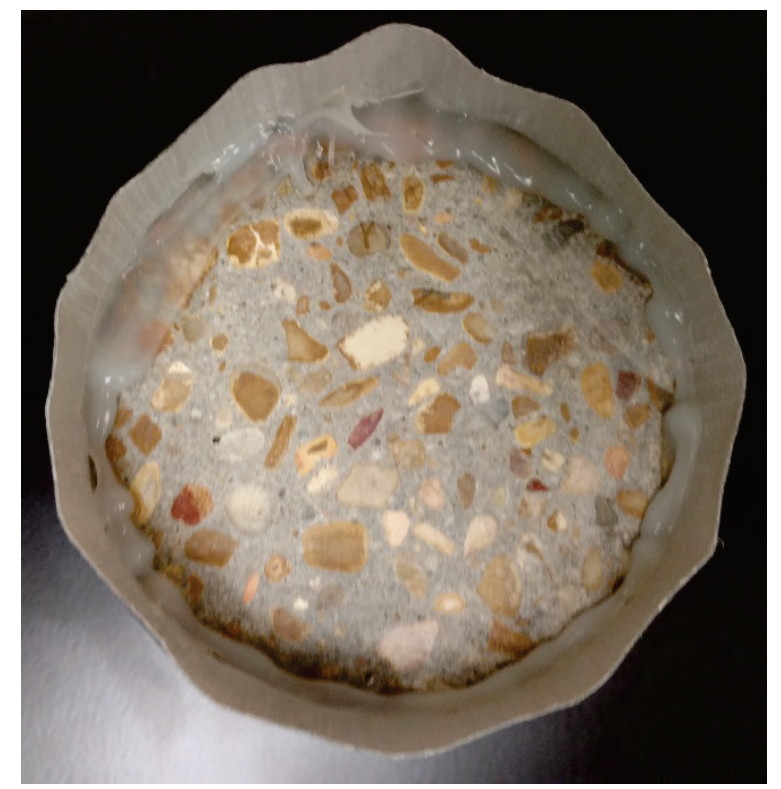


Figure 22. Silicon sealant.

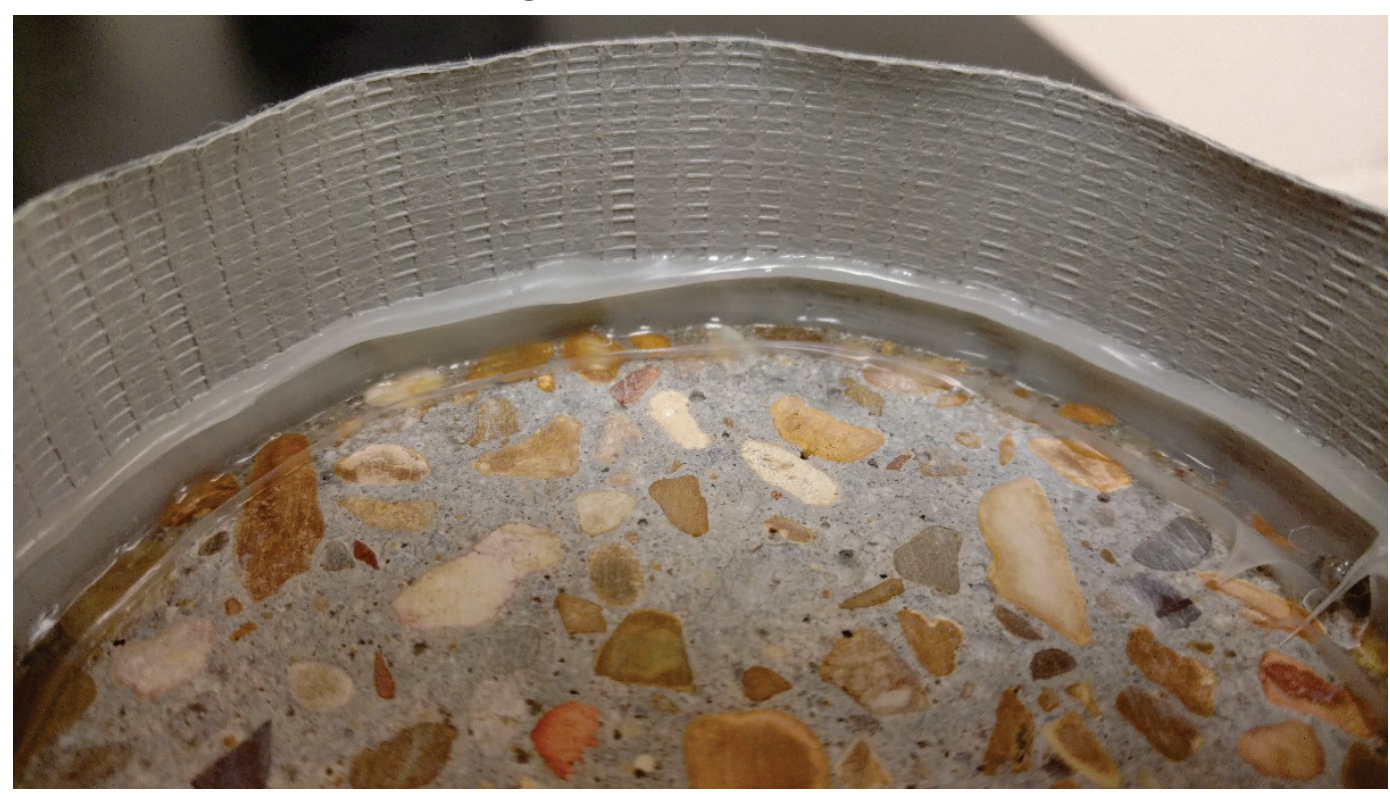




\section{Results}

\subsection{Nondestructive testing}

NDT results were categorized on a scale of damage and deterioration from 1-4 (1 minimal to 4 extreme). An example from the GPR testing is given in Figure 23. As shown in the figure, level 1 corresponded to minimal distortion, level 2 corresponded to surface distortion less than 4 in., level 3 corresponded to surface distortion greater than $4 \mathrm{in}$. and moderate internal reflections, and level 4 corresponded to significant surface and internal reflections beyond 4 in.

Figure 23. GPR damage levels.

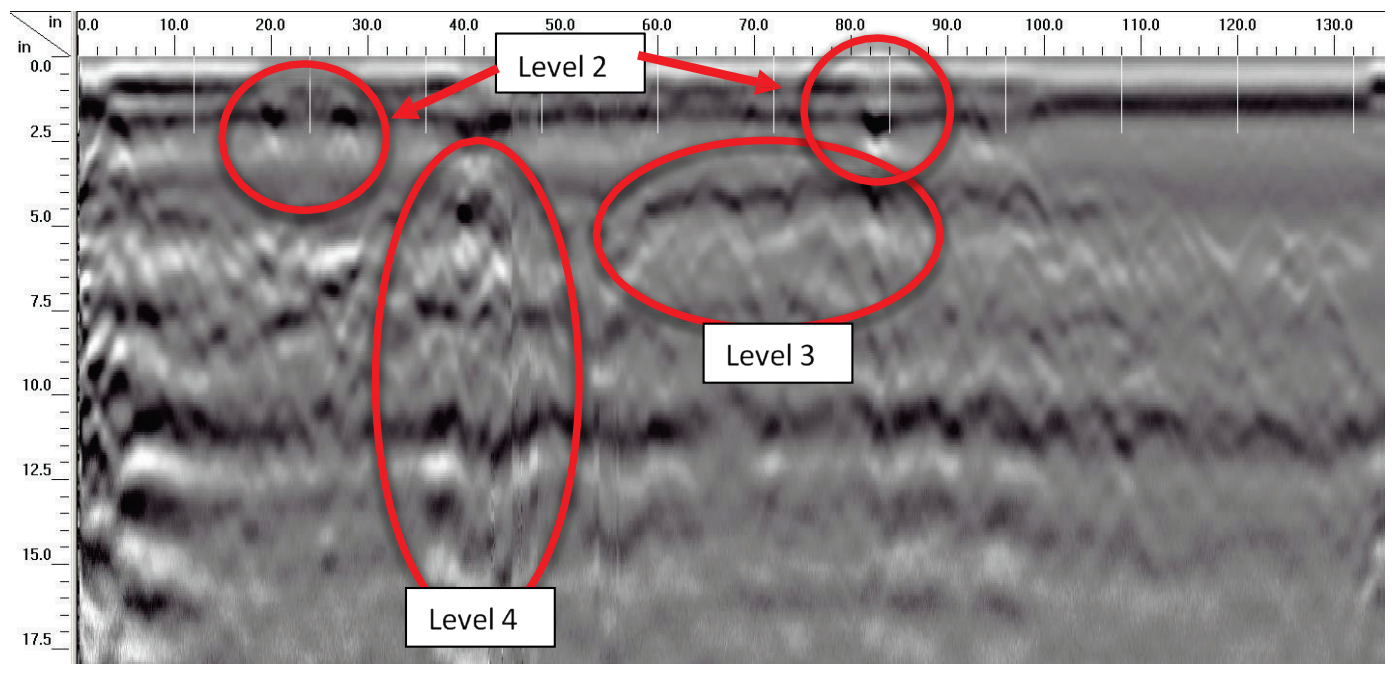

SASW data and MIRA data were more difficult to quantify due to the nature of the data collection and the evaluation process. The scale for these data was based on observations and previous experience. Figures 24 and 25 illustrate the difference between level 1 and level 4 data for SASW and MIRA. Sounding was given either level 1 or level 4 status only. After all data had been evaluated, NDT maps showing the severity of damage were created for each location and NDT type. An example of an NDT map is shown in Figure 26. 
Figure 24. SASW damage levels 1 and 4.
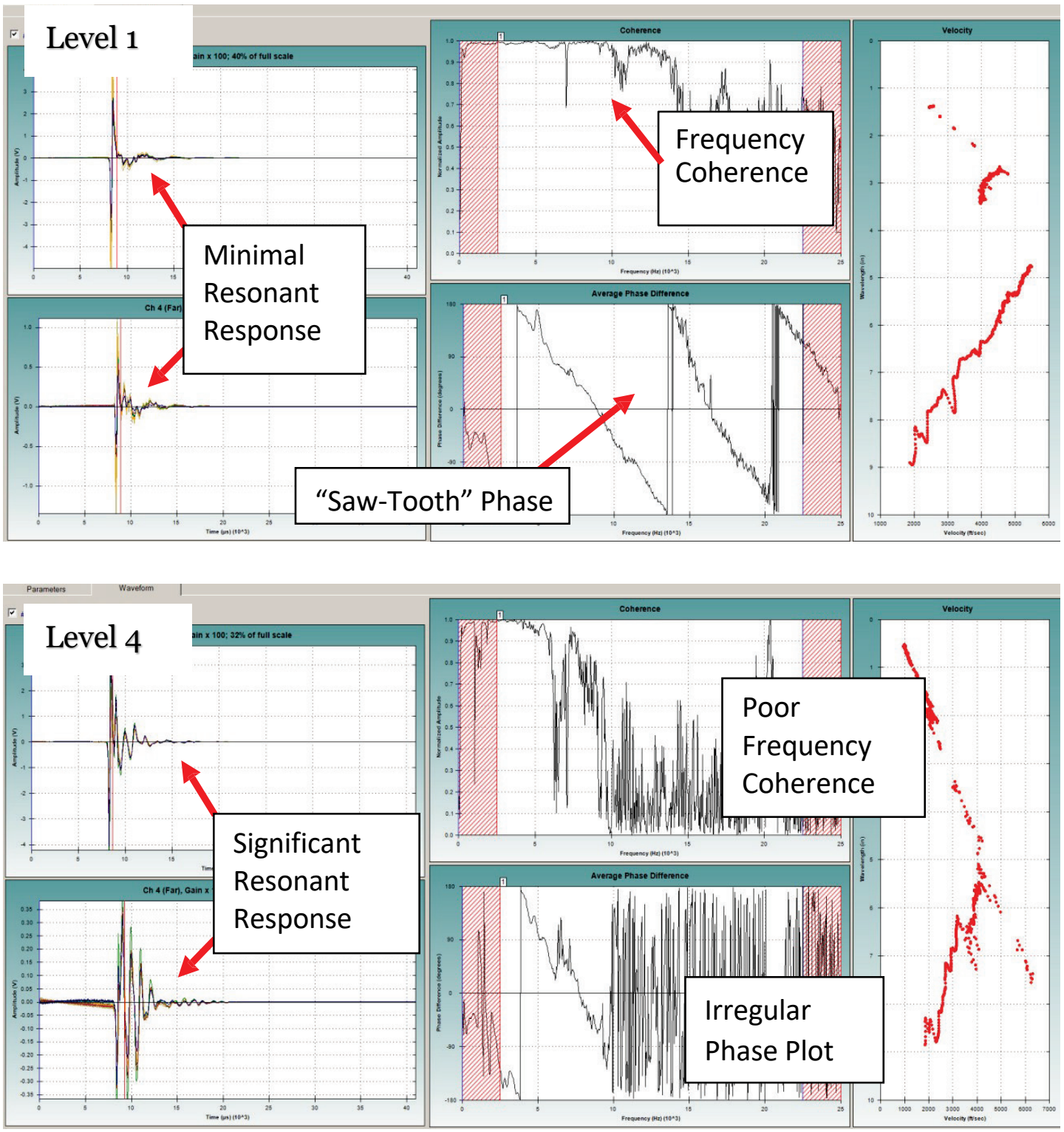
Figure 25. MIRA damage levels 1 and 4.

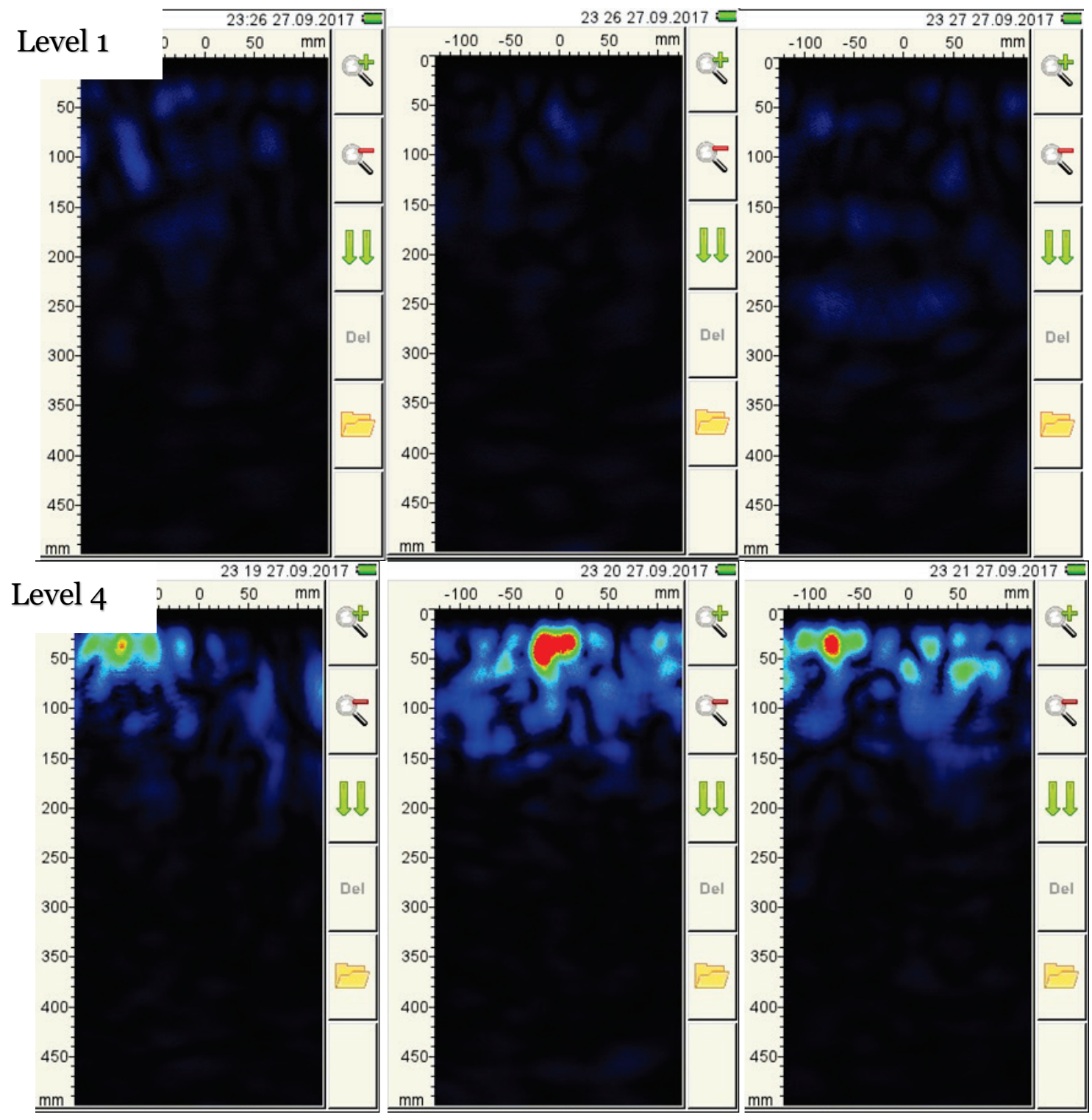


Figure 26. NDT map of L5V with MIRA.

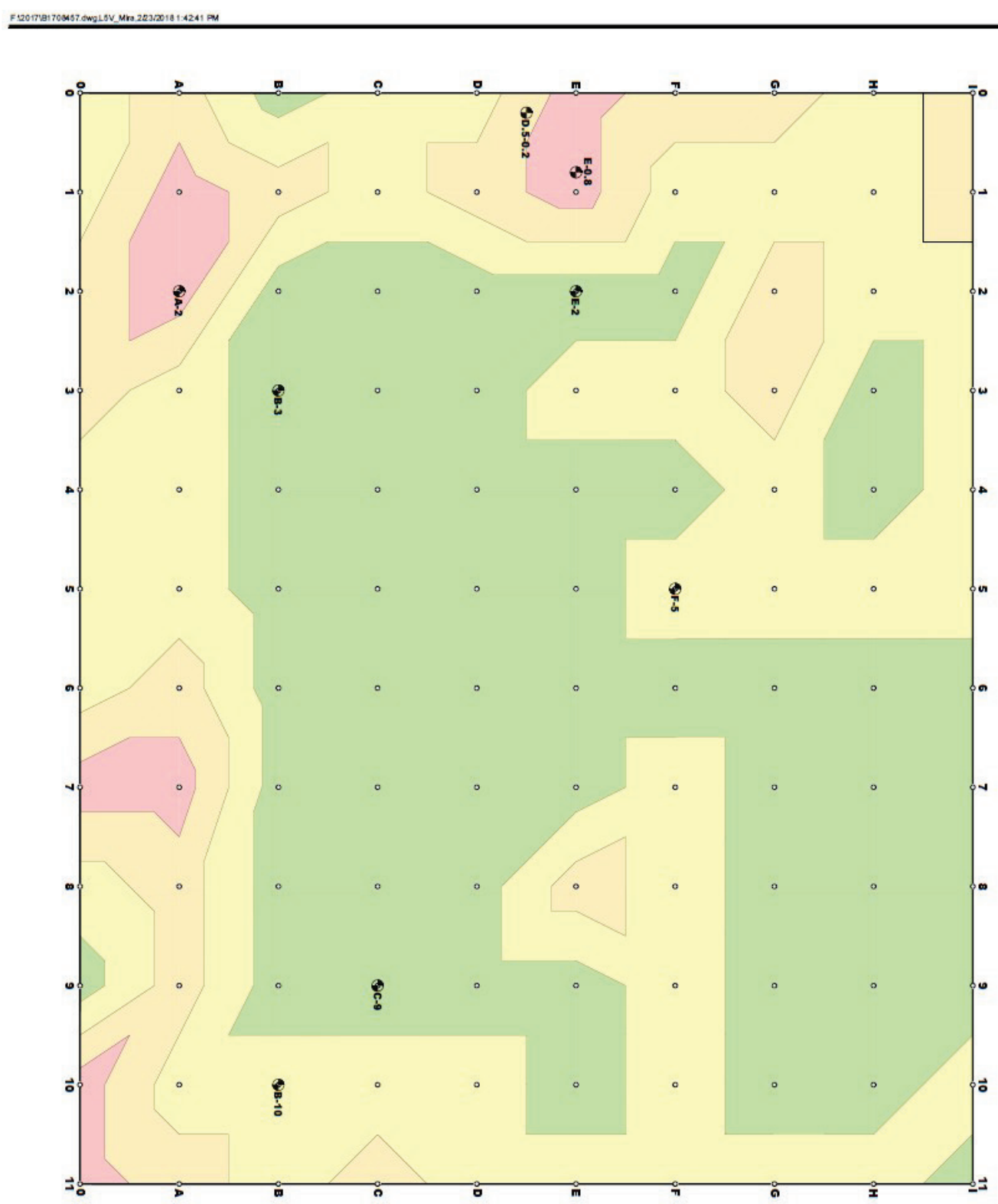

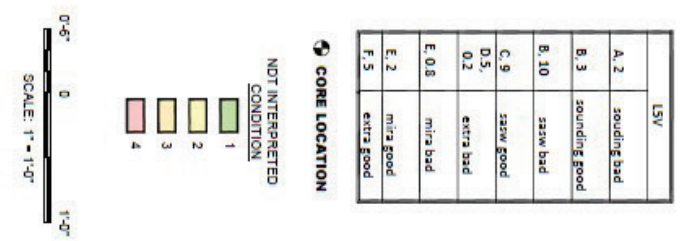

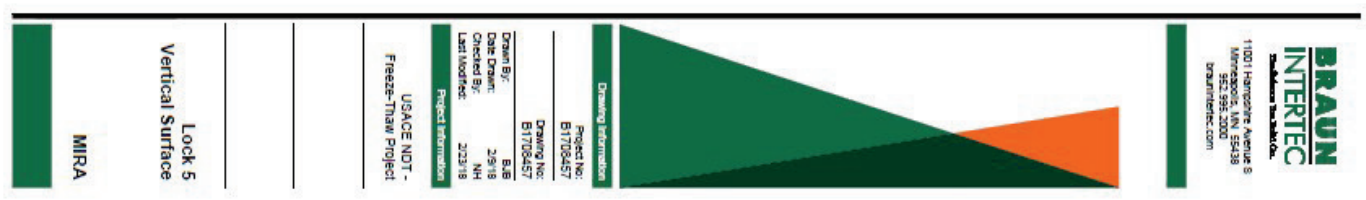




\subsection{Petrography}

Four cores were evaluated using a full petrographic analysis: $\mathrm{L}_{5} \mathrm{H} \mathrm{G-14}$, L5V E-0.8, LSAFH C-13, and LSAFV G.6-11. LSAFV G.6-11 was taken halfway between $\mathrm{G}$ and $\mathrm{H}$. Samples were first photographed as received, then wetted and partially dried to enhance the appearance of fine cracks. Afterwards, samples were sectioned and polished for microscopic evaluations. Figure 27 shows a sample as received and wetted, while Figure 28 shows a sample sectioned and polished. ASR and carbonation depth were also tested, but results are not discussed in this report, as it was not the main area of interest.

All cores appeared to be composed of natural gravel and sand aggregate, and the concrete was fairly well-consolidated with only a minor amount of entrapped air. No supplementary cementitious materials were seen in the samples. Aggregate in all samples appeared to have a maximum size of 2 in., and the paste portion appeared to have a moderately low water-tocement ratio.

The $\mathrm{L}_{5} \mathrm{H}$ core was found to be in fair condition with the condition improving with depth. It exhibited one fracture at 3.9 to $4.1 \mathrm{in}$. and a few surface parallel hairline cracks at depths of 4.7 and $9.6 \mathrm{in}$. Air content was estimated to be 0.5 to $1.5 \%$. Microcracks were present in the outer half of the core.

The $\mathrm{L} 5 \mathrm{~V}$ core was found to be in poor condition with loss of original surface and extensive flaking. The condition of the concrete improved with depth. The core was fractured at depths of 4.7 to $5.1 \mathrm{in}$. and 11.6 to $13.1 \mathrm{in}$. Extensive surface parallel cracking and microcracking were present up to 4.7 in. in depth. Smaller hairline cracks were present in the remainder of the core. Air content was estimated to be 0.5 to $1.5 \%$. Microcracks were common in the outer 5 in.

The LSAFH core was found to be in fair condition with shallow flaking. The condition of the concrete improved with depth. The core was fractured at depths of 2.4 to $3.5 \mathrm{in}$. and 4.3 to $5.3 \mathrm{in}$. A few surface parallel hairline cracks were observed in the outer $5.5 \mathrm{in}$. with a few internal cracks at greater depths. Air content was estimated to be 2 to $4 \%$. Microcracks were common in the outer 5.5 in. 
Figure 27. L5H as received. Right image was taken after wetting to better enhance fine crack definition.
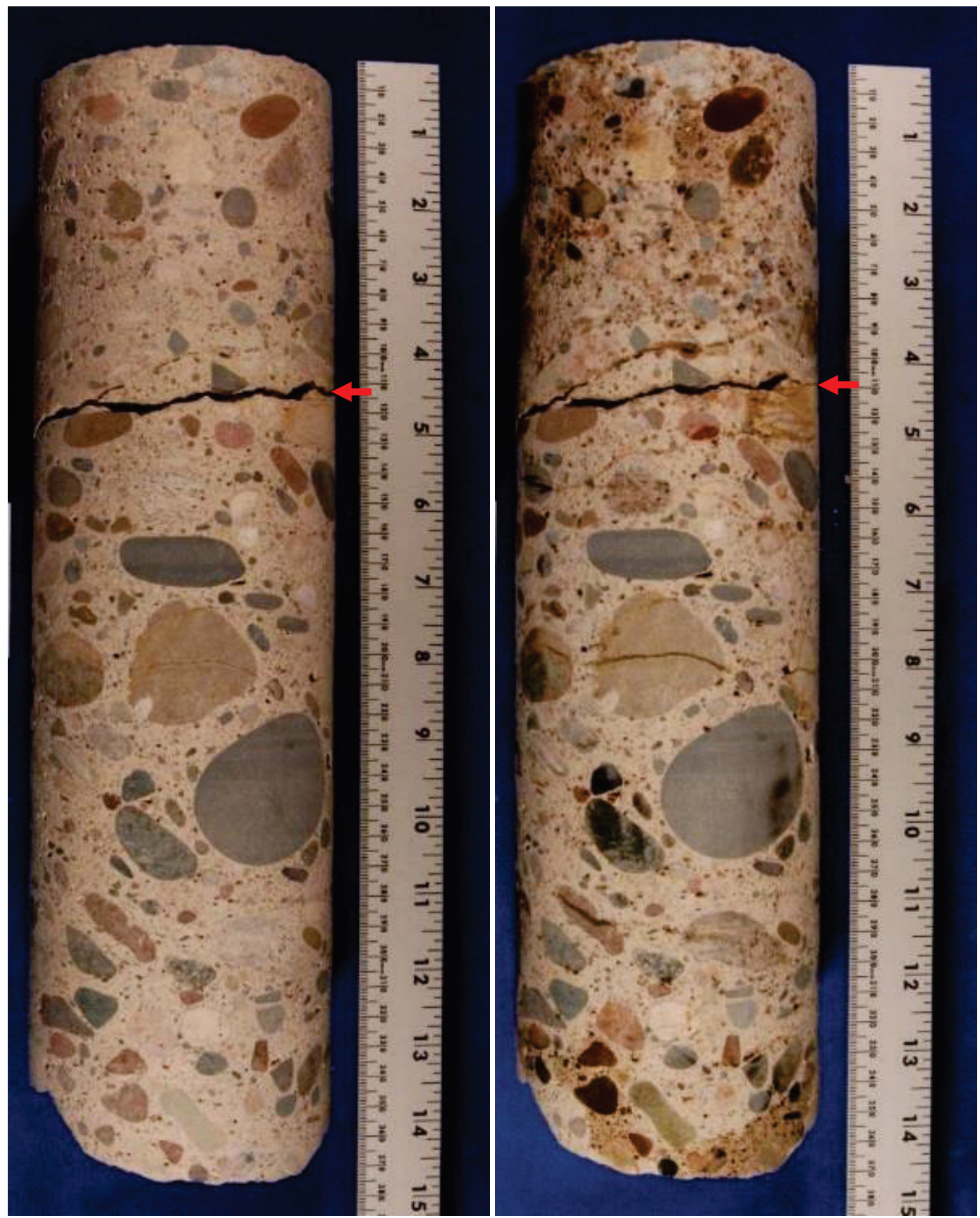

The LSAFV core was found to be in fair condition with shallow erosion of the paste. The condition of the concrete improved with depth. The core was fractured at depths of 2.4 to $3.3 \mathrm{in}$. and 6.5 to $7.5 \mathrm{in}$. A few surface parallel hairline cracks were observed in the outer 7.5 in. with a few internal cracks at greater depths. Air content was estimated to be 2 to $4 \%$. Microcracks were common in the outer 7.5 in. 
Figure 28. L5H as sectioned and polished. Blue arrow shows new concrete. Red arrows mark fractures. Yellow arrows mark saw cuts.

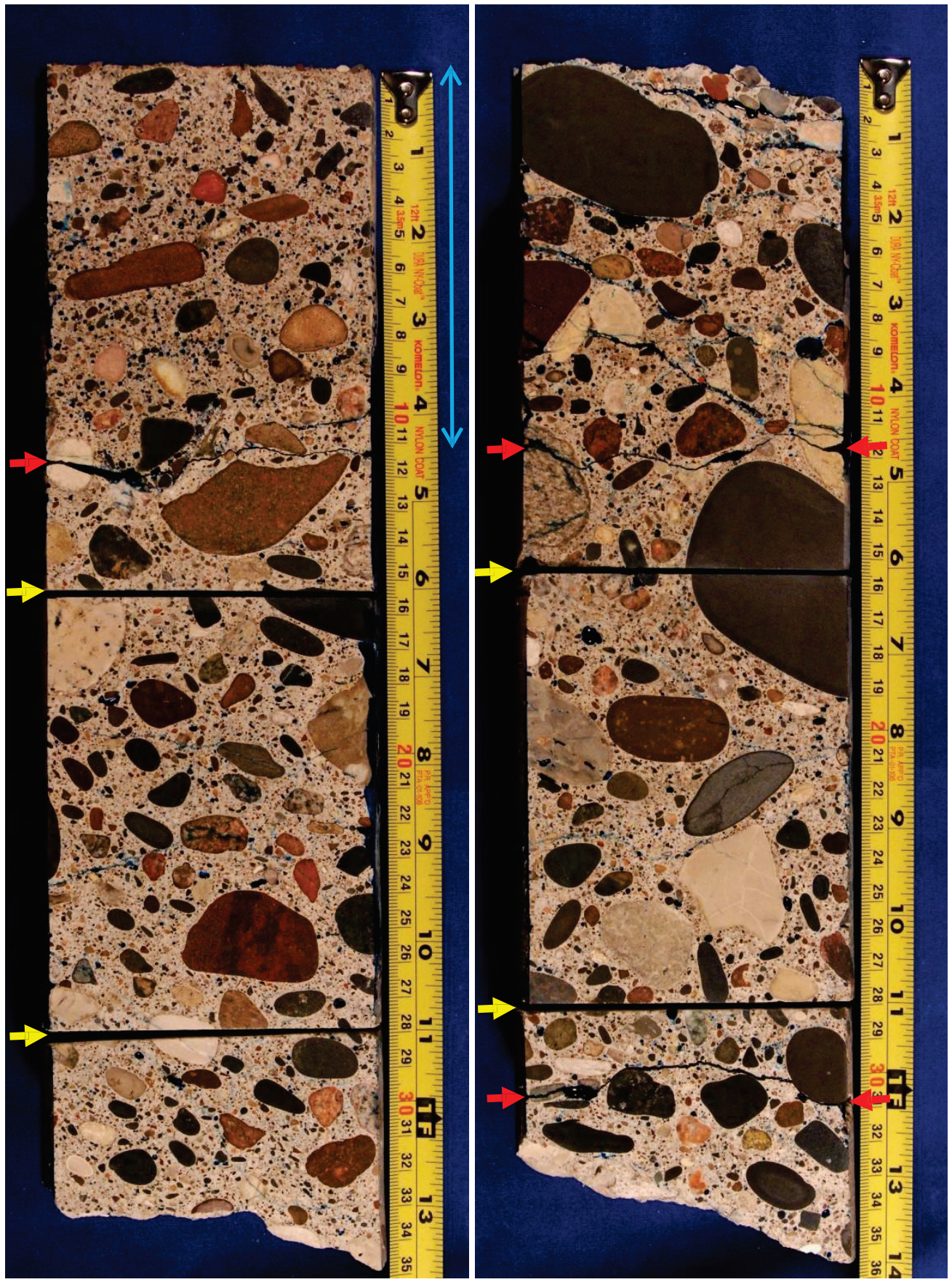

\subsection{Sorption results}

Sorption testing was conducted on the concrete core samples LSAFH C-9 and L5V F-5 sent to ERDC. Sorption measurements were conducted until mass measurements appeared to obtain a second constant slope past the nick point time. Processed sorption data are shown in Figures 29 and 30. 
Linear trend lines were applied to data points before and after nick point time and evaluated for goodness of fit. Trend line pairs that produced the largest coefficient of determination were selected and are in Figures 31, 32, and 33 .

Figure 29. LSAFH C-9 sorption results.

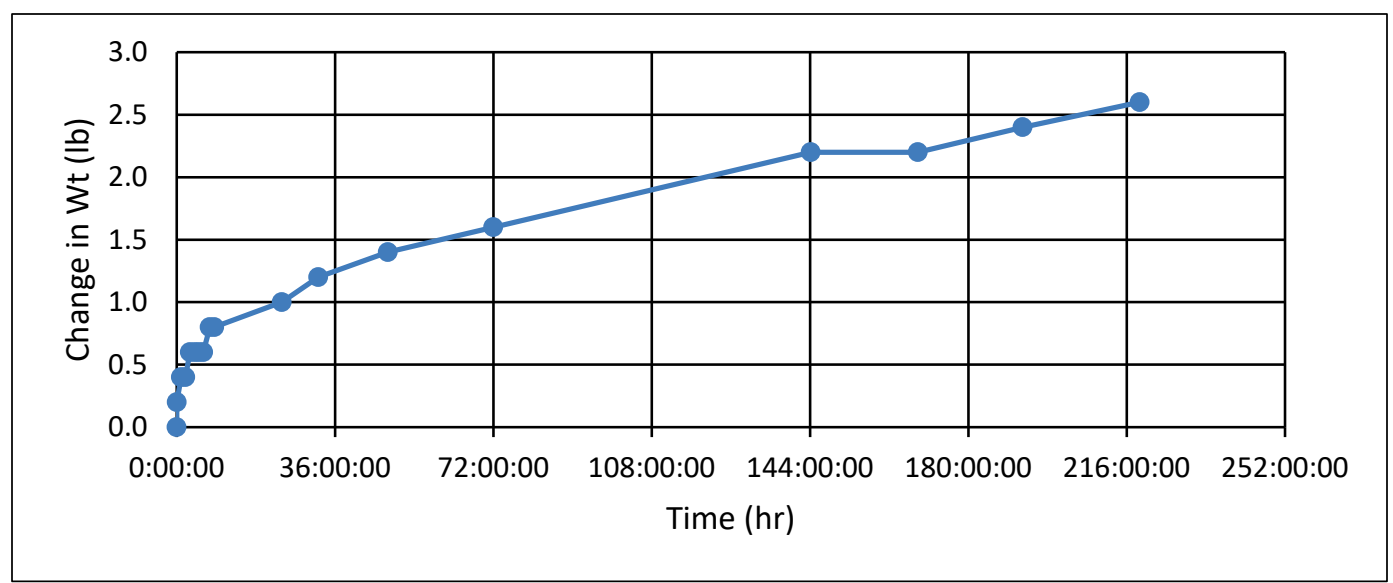

Figure 30. L5V F-5 sorption results.

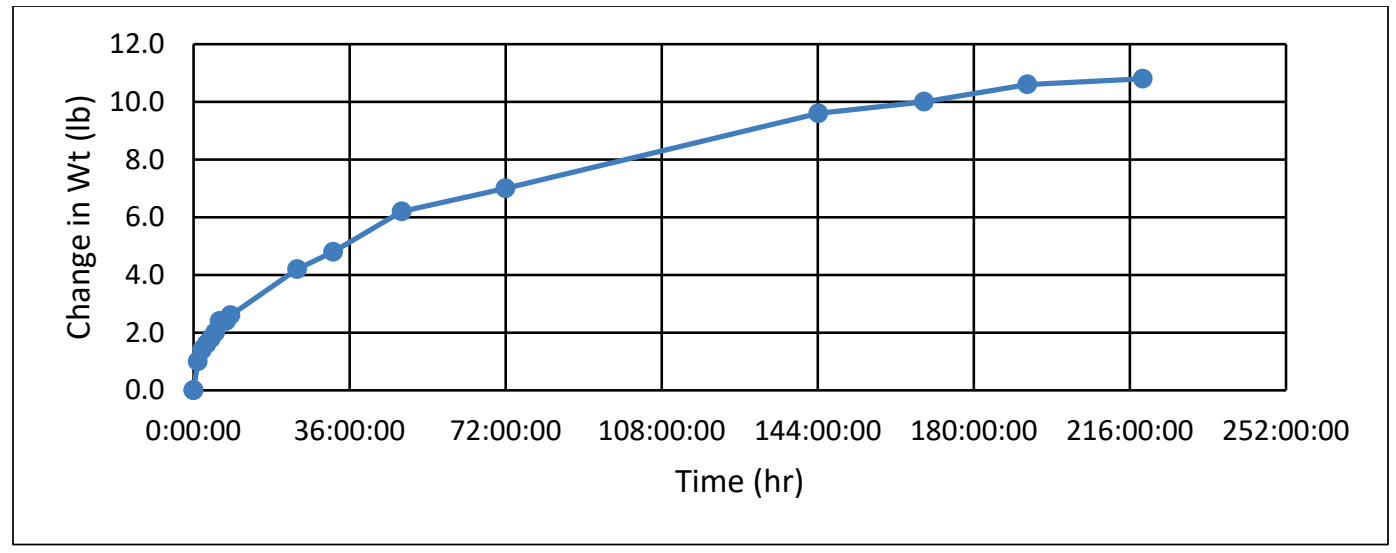

Sorption coefficients were determined using the methodology described in Bentz (2000). The quantitative equation for sorption coefficients before and after nick point time is given in Figure 31, in which mass change (W) is in grams, surface area (A) is in $\mathrm{mm}^{2}$, time (t) is in minutes, density of water $(\rho)$ is 1000 grams $/ \mathrm{mm}$, sorption (I) is in $\mathrm{mm} / \mathrm{min}$, and initial sorption $\left(\mathrm{I}_{0}\right)$ is in $\mathrm{mm}$. The equation was solved graphically by plotting each data point and using a best fit linear trend line. These graphs are shown in Figures 32 and 33. The nick point times were then obtained as the intersection between the two lines. 
Figure 31. Sorption coefficients equation.

$$
\frac{W}{\rho * A}=I \sqrt{t}+I_{0}
$$

Figure 32. LSAFH C-9 sorption coefficients.

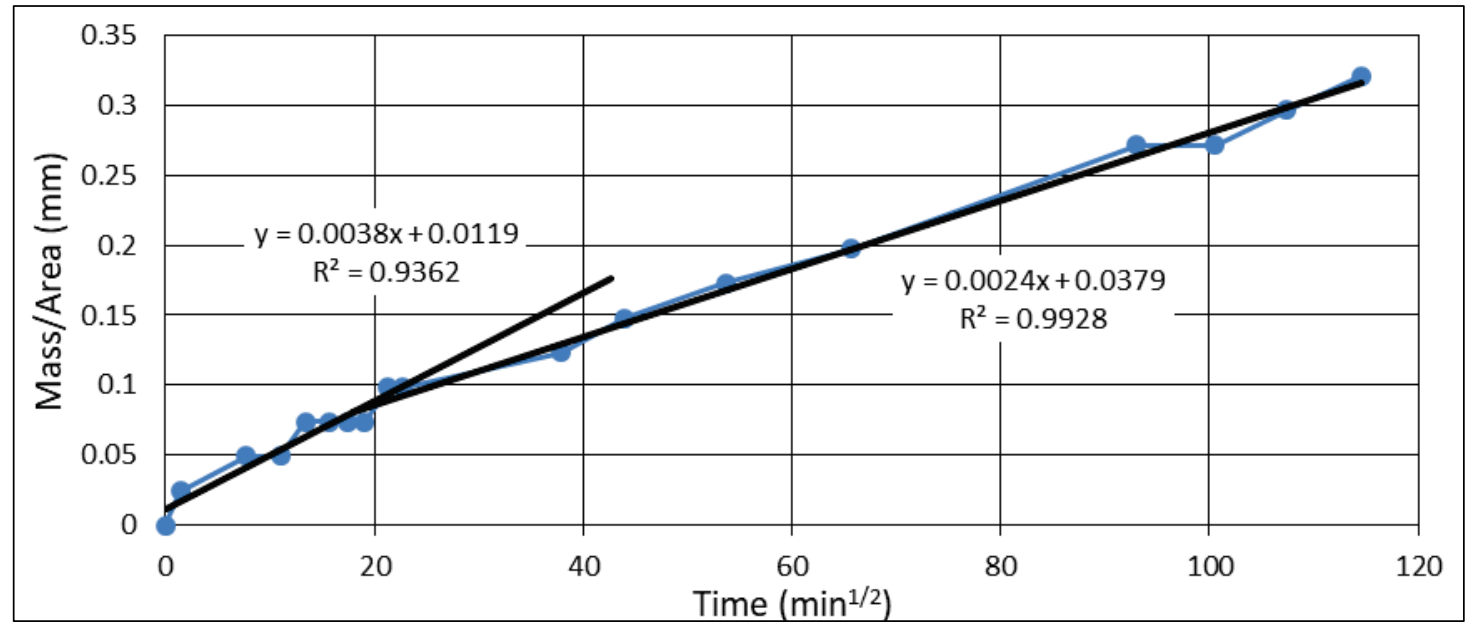

Figure 33. L5V F-5 sorption coefficients.

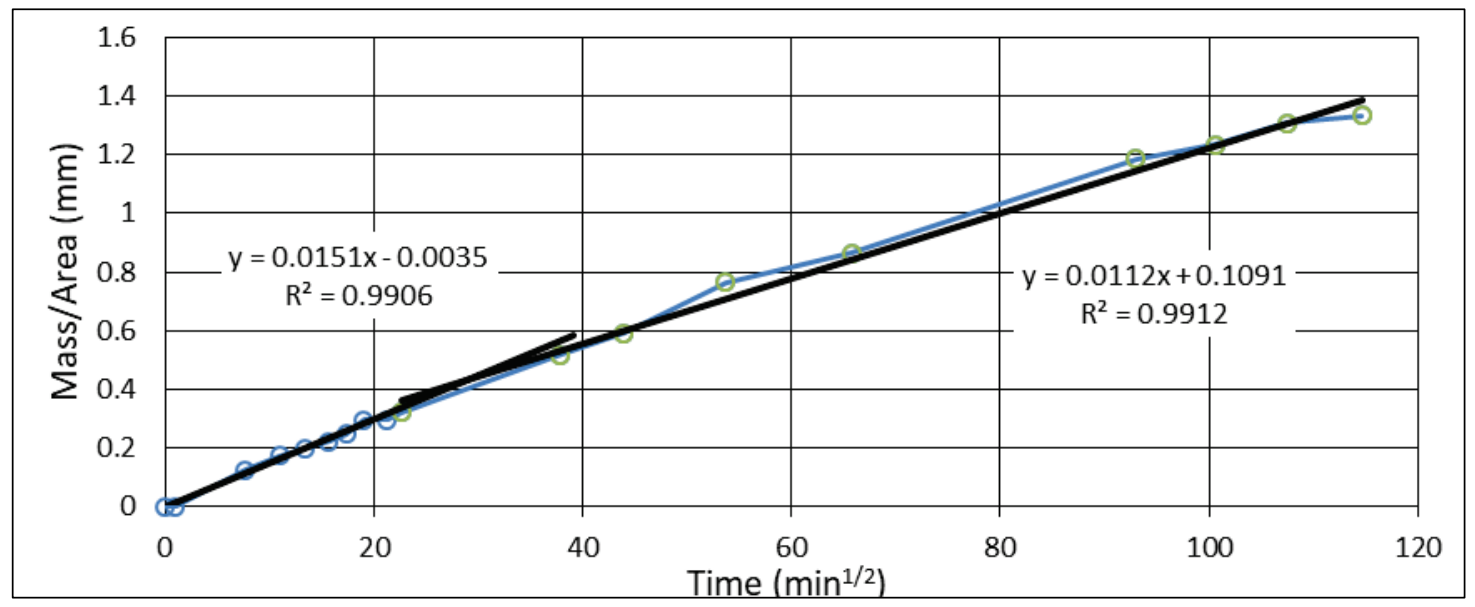

Based on the trend line equations, the sorption and nick point time values are shown in Table 2. Nick point times were rounded to the nearest hour. The Io value for $\mathrm{L}_{5} \mathrm{~V} \mathrm{F-5}$, marked by $\left(^{*}\right)$ in Table 1 , was altered from the original value. According to the graphical method, a negative $\mathrm{I}_{o}$ was obtained, which is not possible. This was the result of the measured change in mass's being equal to zero between the control and the initial mass measurements. For this material, there was no initial mass change. 
Table 2. Measured coefficients for model evaluations.

\begin{tabular}{|c|c|c|}
\hline & LSAFH C-9 & L5V F-5 \\
\hline I early $(\mathrm{mm} / \mathrm{min})$ & 0.0038 & 0.0151 \\
\hline lo early $(\mathrm{mm})$ & 0.0119 & $0.0 *$ \\
\hline Nick point $(\mathrm{hr})$ & 6 & 11 \\
\hline I late $(\mathrm{mm} / \mathrm{min})$ & 0.0024 & 0.0112 \\
\hline Io late $(\mathrm{mm})$ & 0.0379 & 0.1091 \\
\hline
\end{tabular}




\section{Conclusions and Recommendations}

\subsection{Nondestructive testing}

GPR was deemed successful as an evaluation method due to its ability to measure and process large amounts of data quickly. GPR processing times were roughly half that of other NDT methods; however, data accuracy was heavily dependent on the orientation and direction of collection. Based on the core samples, SASW was the most accurate method to predict underlying structural damage. Data were reasonably quick to collect but required a significant portion of data analysis time.

MIRA data were found to be the most sensitive to data collection parameters. Using the correct parameters made it possible to detect data as small as a single aggregate fracture, but using incorrect parameters made even large deformations difficult to detect.

In general the process of formulating a single damage map based on multiple factors was deemed useful in determining critical damage. The technique allowed for results to be verified by multiple methods and reduced the chance of damage being underreported from a single method.

\subsection{Petrography}

Petrography data on L5 cores showed a combination of natural gravel and sand aggregate in non-air entrained cement paste. There were no Supplementary Cementitious Materials (SCMs) detected. The nominal maximum aggregate size was estimated to be 2 in., and the total air content was estimated to be between 0.5 and $1.5 \%$. The concrete appeared to be placed with a low water-to-cement ratio, but due to the age of the concrete, an accurate estimation was not possible. Damage was observed in the approximately $5 \mathrm{in}$. The majority of damage appeared to be due to freeze-thaw with some carbonation present.

Petrography results on LSAF cores were similar in composition, lack of SCMs, aggregate size, and water to cement ratio. The LSAF cores did exhibit a higher air content that was estimated to be between 2 and $4 \%$. Damage was similar in scale and mechanisms. 


\subsection{Sorption evaluations}

The overall goal of the project was to relate the NDT and core findings to service-life modeling calculations. The calculated sorption coefficients were similar to other concrete samples with little to no damage. As mentioned in the introduction, there are unique factors present in navigation structures that increase the probability of freeze/thaw damage. Therefore, even though the sorption coefficients appeared to indicate little to no damage, because this was a navigational structure, it is likely that low values would still correlate to concrete deterioration.

As mentioned in the petrography conclusions, accurate water-to-cement ratios were not possible to estimate due to the advanced hydration state of the cement. It is likely that, because the concrete was in place for an extended period of time before service-life predictions were made, the properties affecting freeze-thaw resistance may have changed greatly.

It should also be noted that sorption testing was conducted on the original concrete, of which the first approximately $5 \mathrm{in}$. had been replaced. Differences in densities and sorptions between the outer concrete and inner concrete may also be present and lead to an under evaluation of sorption coefficients due to an over-evaluation of density.

\subsection{Recommendations for future research}

The methodology behind this service-life modeling approach may make it necessary to conduct all testing on fresh state concrete prior to construction or surface cores immediately after construction in order to achieve the most accurate results. Long-term testing would then be necessary to determine whether the model or sorption coefficients are correctly predicting freeze-thaw damage. It may also be possible to replicate long-term testing using harsh environments with techniques such as ASTM C666 (2015).

It is recommended that a three-pronged approach be conducted to evaluate the model using new, fresh concrete and a variety of testing scenarios. Using a single concrete batch, multiple types of specimens can be created that can be evaluated for freeze-thaw damage based on (1) ASTM C666, (2) extreme environmental conditions, and (3) normal environmental conditions. Concrete can be evaluated for future freeze- 
thaw deterioration by the sorption methodology prior to these testing scenarios and then final data correlated to determine model fit.

This testing regime will allow correlations between the sorption values and the higher potential freeze/thaw damage in navigational structures. Ideally the laboratory data will then be supplemented by additional field studies. The literature and mechanics, as well as the trial laboratory procedure conducted in this report, seem to indicate that the measurement technique is a useful and reliable tool as long as the measurements can be correctly applied to the unique cases under investigation. 


\section{References}

Alexander, M. A., and Y. Ballim. 1993. Experiences with durability testing of concrete: A suggested framework incorporating index parameters and results from accelerated durability tests. In Proceedings of the Third Canadian Symposium on Cement and Concrete, 248-263. Ottawa, Canada.

American Society for Testing and Materials (ASTM). 2013. Standard test method for measurement of rate of absorption of water by hydraulic-cement concretes. C1585-13. West Conshohocken, PA: ASTM International.

. 2015. Standard test method for resistance of concrete to rapid freezing and thawing. Designation: C666M-15. West Conshohocken, PA: ASTM International. . 2017. Standard test method for packaged dry, hydraulic-cement grout (nonshrink). Designation: C1107M-17. West Conshohocken, PA: ASTM International.

. 2018a. Standard test method for obtaining and testing drilled cores and sawed beams of concrete. Designation: C42M-18a. West Conshohocken, PA: ASTM International.

. 2018b. Standard test method for petrographic examination of hardened concrete. Designation: C856-18a. West Conshohocken, PA: ASTM International.

Atkinson, A., and J. A. Hearne. 1990. Mechanistic model for the durability of concrete barriers exposed to sulphate-bearing groundwaters.In Materials Research Society (MRS) Symposium Proceedings, 176:149-156. doi: 10.1557/PROC-176149.

Basheer, P. A. M., S. E. Chidiac, and A. E. Long. 1996. Predictive models for deterioration of concrete structures. Construction and Building Materials 10 (1):27-37.

Bentz, D. P. 2000. A computer model to predict the surface temperature and time-ofwetness of concrete pavements and bridge decks. NISTIR 6551. Washington, DC: U.S. Department of Commerce.

Bentz, D. P., J. R. Clifton, C. F. Ferraris, and E. J. Garboczi. 1999. Transport properties and durability of concrete: Literature review and research plan. NISTIR 6395. Washington, DC: U.S. Department of Commerce.

Bentz, D. P., M. A. Ehlen, C. F. Ferraris, and E. J. Garboczi. 2001. Sorptivity -Based service life predictions for concrete pavements. In Proceedings of the $7^{\text {th }}$ International Conference on Concrete Pavements, 9-13 September, 1:181-193. Orlando, FL.

Chen, F., and P. Qiao. 2015. Probabilistic damage modeling and service-life prediction of concrete under freeze-thaw action. Materials and Structures 48(8):2697-2711.

Fagerlund, G. 1999. Modeling the service life of concrete exposed to frost. International Conference on Ion and Mass Transport in Cement-Based Materials. University of Toronto. 
Jacobsen, S., H. Gran, E. Sellevold, and J. Bakke. 1995. High strength concrete -Freeze/thaw testing and cracking. Cement and Concrete Research 25(8):17751780.

Li, W., M. Pour-Ghaz, J. Castro, and J. Weiss. 2012. Water absorption and critical degree of saturation relating to freeze-thaw damage in concrete pavement joints. Journal of Materials in Civil Engineering 10.1061/ (ASCE) MT.19435533.0000383, 299-307.

Marion, W., and K. Urban. 1995. User's manual for TMY2s- Typical meteorological years. Washington, DC: National Renewable Energy Laboratory.

Prado, P. J., B. J. Balcom, D. S. Beyea, T. W. Bremner, R. L. Armstrong, and P. E. Grattan-Bellow. 1998. Concrete freeze/thaw as studied by magnetic resonance imaging. Cement and Concrete Research 28(2):261-270.

Zhou, T., M. Z. Bazant, and R. J. Pellenq. 2015. Modeling freeze-thaw in concrete. MIT CSHub Research Brief Iss. 5. Cambridge, MA: Massachusetts Institute of Technology. 


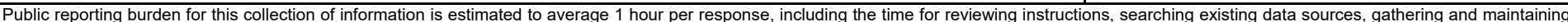

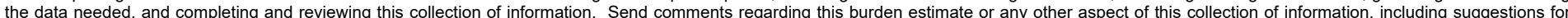

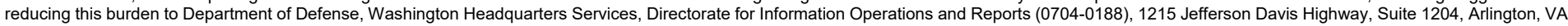

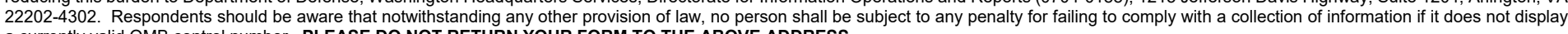
a currently valid OMB control number. PLEASE DO NOT RETURN YOUR FORM TO THE ABOVE ADDRESS.

\begin{tabular}{|l|l|l} 
1. REPORT DATE (DD-MM-YYYY) & 2. REPORT TYPE & 3. DATES COVERED (FrOm - To)
\end{tabular} July 2019

\section{TITLE AND SUBTITLE} Final

Predicting Service Life Utilizing Freeze-Thaw Modeling of Aging Navigation Structures 5a. CONTRACT NUMBER

Predicting Service Life Utilizing Freeze-Thaw Modeling of Aging Navigation Structures

\section{5b. GRANT NUMBER}

5c. PROGRAM ELEMENT NUMBER

\section{AUTHOR(S)}

Jameson D. Shannon, Robert D. Moser, and Stephanie G. Wood

5d. PROJECT NUMBER

476923

5e. TASK NUMBER

5f. WORK UNIT NUMBER

\section{PERFORMING ORGANIZATION NAME(S) AND ADDRESS(ES)}

Geotechnical and Structures Laboratory

U.S. Army Engineer Research and Development Center

3909 Halls Ferry Road

Vicksburg, MS 39180-6199

\section{SPONSORING / MONITORING AGENCY NAME(S) AND ADDRESS(ES)}

U.S. Army Engineer Research and Development Center

3909 Halls Ferry Road

Vicksburg, MS 39180-6199

12. DISTRIBUTION / AVAILABILITY STATEMENT

Approved for public release; distribution is unlimited.

\section{SUPPLEMENTARY NOTES}

\section{ABSTRACT}

This effort was undertaken as a part of the Service Life Modeling of Aging Navigation Structures 6.1 basic research program. Due to the increasing required service life of our infrastructure, additional evaluation tools are necessary to determine whether concrete mixture designs will meet the higher levels of design requirements and useful life. Additionally, these tools may be used as predictive damage analysis techniques to evaluate when critical damage will occur, and potential remedies are applied to bring structures back into operation parameters. This report features non-destructive test methods, coring and petrography, and service-life-based sorption measurements to evaluate two existing navigation structures. Concrete sections and samples were evaluated for damage using multiple methodologies, and comparisons were made to attempt to correlate damage depth and mechanisms with the sorption data.

\begin{tabular}{|lll}
\hline 15. SUBJECT TERMS & & Concrete Deterioration \\
Concrete Service Life & Navigation & Non-Destructive Test Methods \\
Modeling & Concrete - testing & Navigational Structures \\
\hline
\end{tabular}
16. SECURITY CLASSIFICATION OF: a. REPORT Unclassified

\section{c. THIS PAGE}

Unclassified
17. LIMITATION OF ABSTRACT
Unclassified
8. PERFORMING ORGANIZATION REPORT NUMBER

ERDC/GSL TR-19-33

10. SPONSOR/MONITOR'S ACRONYM(S)

ERDC

11. SPONSOR/MONITOR'S REPORT NUMBER(S)
Hydraulic structures - maintenance and repair

Hydraulic structures - evaluation

Hydraulic structures - frost damage

18. NUMBER 1 19a. NAME OF RESPONSIBLE OF PAGES

44 19b. TELEPHONE NUMBER (include area code) 